\title{
Energy Separation for Ranque-Hilsch Vortex Tube: A short review
}

\author{
Zhuohuan $\mathrm{Hu}^{\mathrm{a}}$, Rui Li ${ }^{\mathrm{a}}$, Xin Yang ${ }^{\mathrm{a}}$, Mo Yang ${ }^{\mathrm{a}}$, Rodney Day ${ }^{\mathrm{b}}$, Hongwei Wu ${ }^{\mathrm{b}, *}$ \\ ${ }^{a}$ Shanghai Key Laboratory of Multiphase Flow and Heat Transfer in Power Engineering, School of \\ Energy and Power Engineering, University of Shanghai for Science and Technology, Shanghai, 200093, \\ China \\ ${ }^{b}$ School of Engineering and Computer Science, University of Hertfordshire, Hatfield, AL10 9AB, UK \\ *Corresponding author. Email: h.wu6@herts.ac.uk; Tel. +44(0)1707284265
}

\begin{abstract}
:
In this article, the development of the energy separation for the vortex tube has been briefly reviewed. This review mainly focuses on three aspects, they are the energy separation principle, the design criteria of vortex tubes, and practical application. First, the research progress on the energy separation principle of the vortex tube from several aspects has been introduced, such as friction, pressure gradient, acoustic streaming, secondary circulation and multi-circulation theory. In addition, the control factors that affecting the performance of the vortex tube were summarized. Furthermore, due to its simple structure, safety and stability, the vortex tube is widely used in the field of refrigerating and heating, mixture separation. This survey, while extensive cannot cover all papers, some selection is necessary. The purpose of this review aims to summarize the important works of literature on the energy separation of vortex tube as well as identify limitations to existing studies and directions for future research.
\end{abstract}

Key word: vortex tube, energy separation, principle, application

\section{Introduction}

The vortex tube is an ingenious thermal device, which can divide the compressed air into a low temperature region and a high one without any moving mechanical components. The vortex tube effect was firstly observed by Ranque, a French metallurgist, who presented a report on the vortex tube effects at an academic conference in $1933^{1}$. Unfortunately, their research investigation was not accepted by the scientific community. The researches on the vortex tube were shelved for several years until an experimental test result of vortex tube was published by the German engineer Hilsch. In 1947, Hilsch delivered a comprehensive study on the vortex tube ${ }^{2}$. Their study not only explained the working principle of the vortex tube effects, but also discussed the factors which have impact on the energy separation efficiency in detail. In memory of the two founding scientists, the vortex tube is also known as the Hilsch Vortex Tube (HVT), Ranque Vortex Tube (RVT), Ranque-Hilsch Vortex Tube (RHVT). Although there are several different names, only Vortex Tube will be used in this paper. 
A vortex tube is usually composed of one or more inlet nozzles, a hot end tube, a vortex chamber, a cold orifice and a control valve or a plug which is located at the hot end. The hot exit is located at the periphery while the cold exit at the centrality. The exits are arranged at one or both sides of the tube. When the compressed gas tangentially injects into the RHVT through the nozzles, highly vortical flow is formed inside the vortex chamber, and moves to the opposite end. The peripheral part of the flow escapes from the hot exit at a temperature which is higher than that at inlet. The core part of the flow is forced back by the control valve in a counter-flow RHVT, and escapes from the cold orifice at the opposite end under a temperature lower than that at the inlet. The airflow in a counter-flow RHVT is shown in Fig. 1. In a uni-flow RHVT, the cold exit is at the same end with the hot exit. The airflow in the uni-flow RHVT is presented in Fig. 2.

\section{Inlet nozzles}

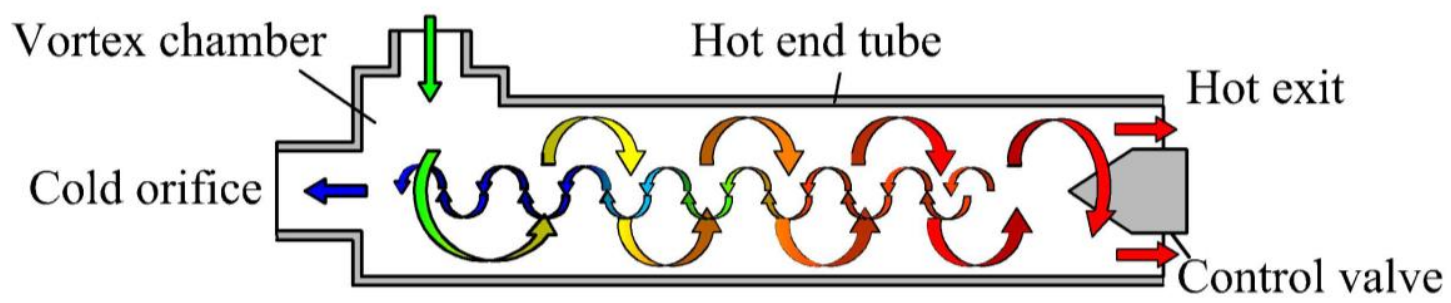

Fig. 1 Schematic drawing of counter-flow RHVT

Inlet nozzles

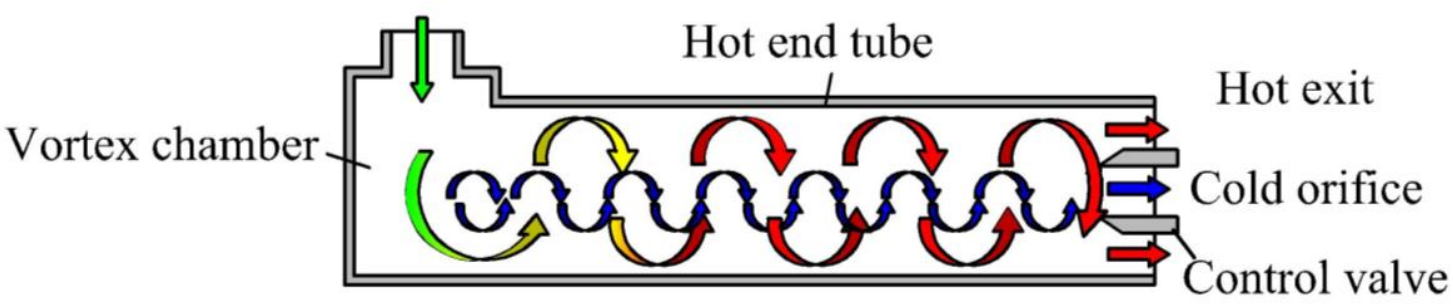

Fig. 2 Schematic drawing of the uni-flow RHVT

Since the vortex tube effect was discovered in the 1930s, many researchers have made much effort on the mechanisms afterwards. All of these research works made significant contributions to the study on the vortex tube. However, the explanation and physical mechanism of the energy separation phenomenon is still far from complete until now. Therefore, an accurate description of the flow field in the vortex tube is necessary to reveal the principle of the energy separation. Smith ${ }^{3}$, Aydin ${ }^{4}$, et. al. have considered different control factors in the exploration of the vortex tube effect principle, including friction, pressure gradients, acoustic streaming and secondary circulation. All these factors have not been proven to be the real reasons through additional research, some researchers ${ }^{5,6}$ even obtained opposite conclusions. Some of the most representative theories will be described in this literature.

By contrast, the energy separation efficiency of the vortex tube is lower than other devices. Nowadays seeking feasible methodologies to improve energy 
separation efficiency has attracted extensive attention. It is generally recognized that there are many variables influencing the flow performance of the vortex tube, which are mainly reflected in two aspects: the geometries of the vortex tubes ${ }^{7-12}$, such as the length diameter ratio ${ }^{13}$, number of the inlet nozzles ${ }^{14}$; parameters of the working fluid $^{15}$, for instance, inlet pressure ${ }^{16}$ and inlet temperature ${ }^{17}$. In order to improve the vortex tube efficiency, some optimisation methods are applied to the vortex tube design as well ${ }^{18-22}$.

It is noted that the vortex tube has some advantages such as simplified structure, stable operation, low cost and durability. The absences of mechanical moving part or chemicals which allow the device to work without the risk of spark or explosion make it suitable for applications. Vortex tube can achieve cooling, heating, separation, vacuum extraction and other function, but the low thermal efficiency and small refrigerating capacity limit its wide application. When the cooling capacity and efficiency can be ignored, the advantages of the vortex tubes make them attractive in industrial application. Nowadays the vortex tube has been widely used in both the cooling and heating application ${ }^{23}$, gas drying ${ }^{24}$, electric production, gas mixture separation $^{25}$, DNA applications ${ }^{26}$ and other purposes ${ }^{27-31}$.

\section{The working principle of a Vortex Tube}

Compared with the simple structure of the vortex tube, the flow field inside the vortex tube is quite complex. This section will introduce the flow field in the vortex tube and several temperature separation theories.

\subsection{The flow field}

In order to explain the vortex tube effect, a clear understanding of the flow field in the vortex tube is essential. Many researchers have done a substantial amount of research on the flow field. Roy ${ }^{32}$ injected the dye into the vortex tube to study the flow field in the tube. Smith ${ }^{3}$ used smoke to investigate the flow pattern, and the velocity distribution obtained by these methods was similar to Rankine vortex. The double helix structure of the working fluid in the vortex tube was observed by the Hilbert double filtering method in $1997^{33}$. Xue ${ }^{34}$ used air bubbles and small plastic particles to trace the flow structure and presented the multi-circulation theory.

It is necessary to measure the temperature, pressure and velocity of the fluid to better understand the flow field in more details. The laser Doppler method would be the most accurate measurement technique to obtain the velocity components of the flow field ${ }^{35}$. Neverthless this method cannot be applied to the vortex tube on account of its high centrifugal acceleration. In 2012, Xue ${ }^{36}$ used a cobra probe for three-dimensional (3D) velocity gauging. The structure of the cobra probe is illustrated in Fig. 3. There are 45 degree angles between the two adjacent faces. The traditional porous probe can only measure the average velocity, while the cobra probe can capture the data of transient velocity, mean velocity, Reynolds stress and other parameters from complex three-dimensional turbulent flow field. Besides, the width of the probe is only $1.4 \mathrm{~mm}$, which can reduce the interference of the probe to the flow field ${ }^{37}$. In Xue's experiments, the cobra probe can gauge wind speed of 10 to 50 $\mathrm{m} \cdot \mathrm{s}^{-1}$, above the Pitot tube. The stagnation and static pressures can be obtained by 
Pitot tube, the velocity can be calculated using the formula 1 .

$$
p_{s g}=p_{s t}+\frac{\rho v^{2}}{2}
$$

where $p_{\text {sg }}$ is the stagnation pressure, $p_{\text {st }}$ is the static pressure, $\rho$ is the flow density and $v$ is the flow velocity.

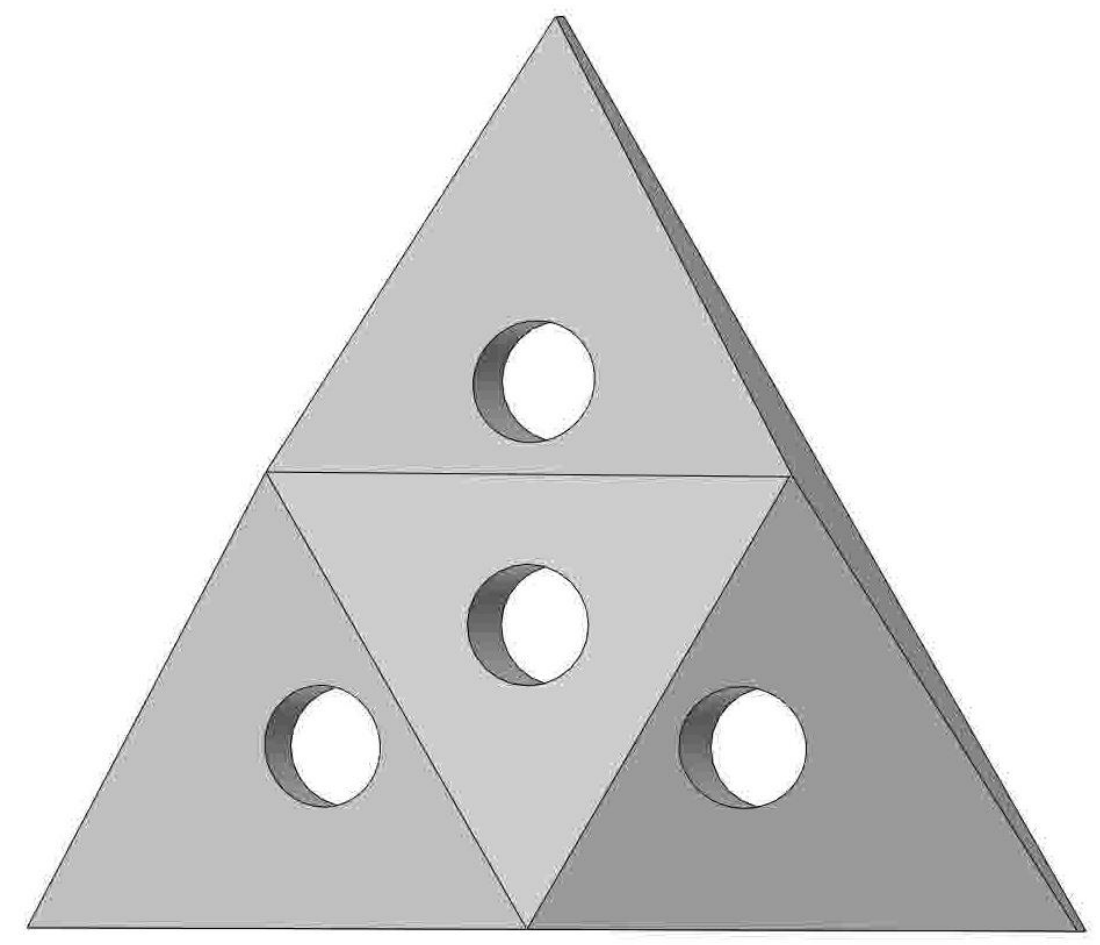

a) The shape of probe's head

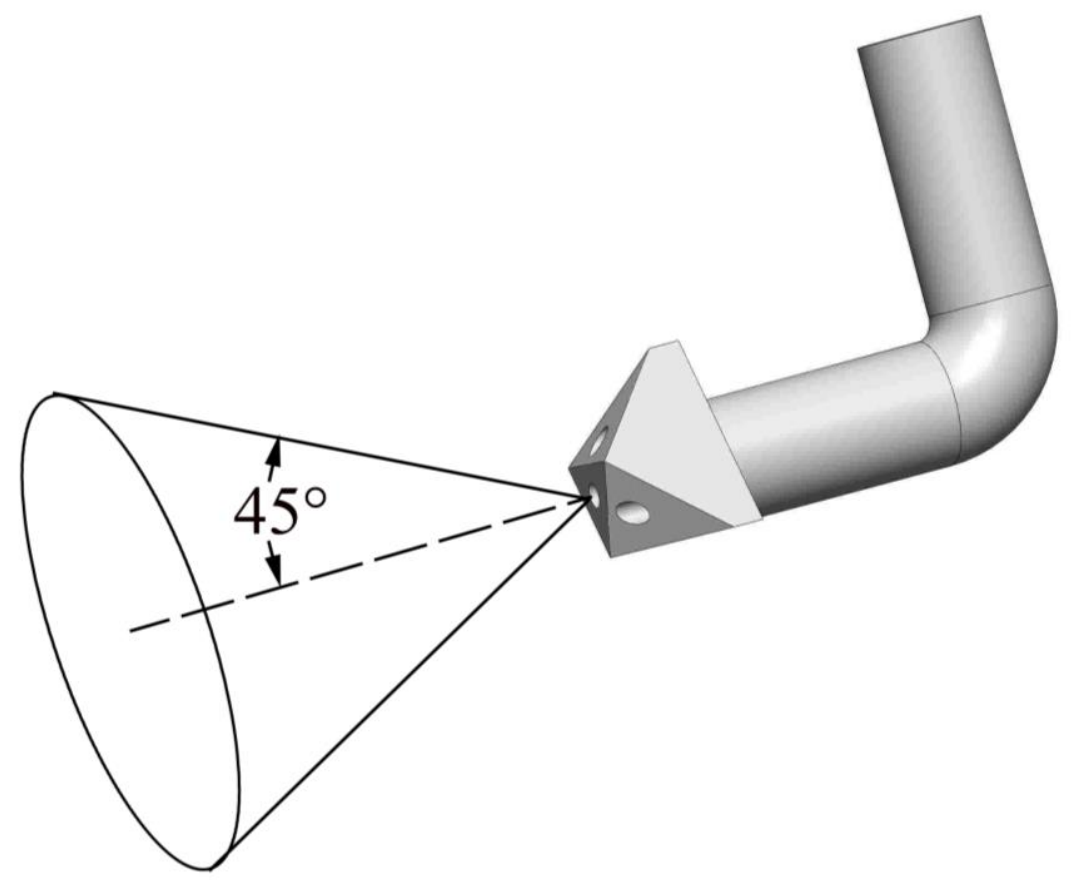

b) Measuring range

Fig. 3 Sketch of the cobra probe 
The pressure profiles at any position in the tube could be determined by rotating and shifting. The Pitot tube can only be used to acquire the mean pressure, yet it is not suitable for measuring the turbulence parameters because of the relatively long response time ${ }^{38}$. The accuracy will be not enough when the Mach number is lower than 0.25 . More accurate data is capable to be obtained with hot-wire anemometry. The principle of the device is based on the balance of the convection heat transfer from a heated wire located in a flowing fluid. The comparison of the Pitot tube and hot-wire techniques was discussed in detail by $\mathrm{Gao}^{39}$.

With the development of modern numerical technology, numerical simulations began to be accepted for analyzing the principle of energy separation. The flow field of vortex tube was simulated using a variety of turbulence models, like the standard k- $\varepsilon$ model $^{40-43}$, LES model ${ }^{44-46}$, and algebraic Reynolds stress model ${ }^{47}$. Baghdad ${ }^{48}$ found that the simulation results of some turbulence models (k- $\varepsilon$ model、k- $\omega$ model、 SST k- $\omega$ model、RSM model) can reflect the energy separation phenomena. It must be emphasized that the numerical simulation method actually depends on the equation model, therefore, the experimental comparison is necessary to validate against the numerical results. Zhang ${ }^{49}$ studied the dynamic process of the steady flow in vortex tube by numerical calculation. Transition Reynolds Stress Model was selected as the numerical model. After dynamic convergence, the flow field results showed that the typical periodic large-scale fluid flow structure could be observed. The unstable flow of the high intensity vortex causes the vortex breakdown ${ }^{50}$ and generates precession vortex core. The periodic motion of the precession vortex core around the centre line of the tube leads to the oscillation of the pressure field and velocity field. Therefore, it is proposed that the precession vortex core motion is one of the factors that affecting the energy transfer in the vortex tube. The boundary motion or vibration of the reverse flow zone promotes the particles to travel between the high pressure and the low pressure zones at a certain vibration frequency. Particles are compressed to release heat in the external vortex flow which is in the high pressure zone, and expand to absorb the heat in the reverse flow zone where the pressure is low.

\subsection{Pressure gradient}

As the founder of the research on vortex tube, Ranque ${ }^{1}$ believed that the main reason for energy separation probably is adiabatic expansion in the central region and adiabatic compression in the peripheral region. Some researchers agreed with this statement ${ }^{51-54}$. In addition, the static pressure distribution along the vortex tube was demonstrated by $\mathrm{Xue}^{36}$. It was indicated that the peripheral pressure is higher than the central. The temperature drop near the injection caused by adiabatic expansion can be express as ${ }^{55}$ :

$$
T_{\mathrm{in}}-T_{\mathrm{i}}=\frac{\gamma-1}{2 R \gamma} \omega^{2}\left(R_{\mathrm{t}}^{2}-r^{2}\right)
$$

where $T_{\mathrm{in}}$ and $T_{\mathrm{i}}$ are the inlet temperature and peripheral temperature respectively, $R$ is the gas constant, $\gamma$ is the specific heat ratio of the air flow, $\omega$ is the angular velocity, $R_{\mathrm{t}}$ is the radius of the vortex tube and $r$ is the radial location.

However, there has been a controversy about the reliability of pressure gradient 
theory. If the pressure gradient is the main reason for the energy separation, it means that the working medium must be compressible. As a result, Balmer ${ }^{56}$ selected high pressure liquid water as the working medium during the experiment, their result indicated that the energy separation effect still existed even if the media was liquid. It was concluded that the pressure gradient theory is not perfect enough, and more working materials need to be considered in the future work.

\subsection{Viscous-Shear Theory}

Hilsch $^{2}$ had similar interpretation on temperature separation with Ranque, and added that the friction between different layers of flow may be an important reason for temperature separation. Fulton ${ }^{57}$ developed a theory of forced vortex and free vortex which stated that: When the compressed gas is ejected from the nozzle at high speed, the angular velocity at the peripheral location is lower than that of the central location, and an almost free vortex is formed near the inlet nozzle. Under the action of internal friction, the fluid of the section rotates at the same angular velocity, which is similar to the rotational motion of a rigid solid. In the process, mechanical energy transfers from the inner layer to the outer fluid, whereas the diffusion energy flows in the opposite direction, as shown in Fig. 4.

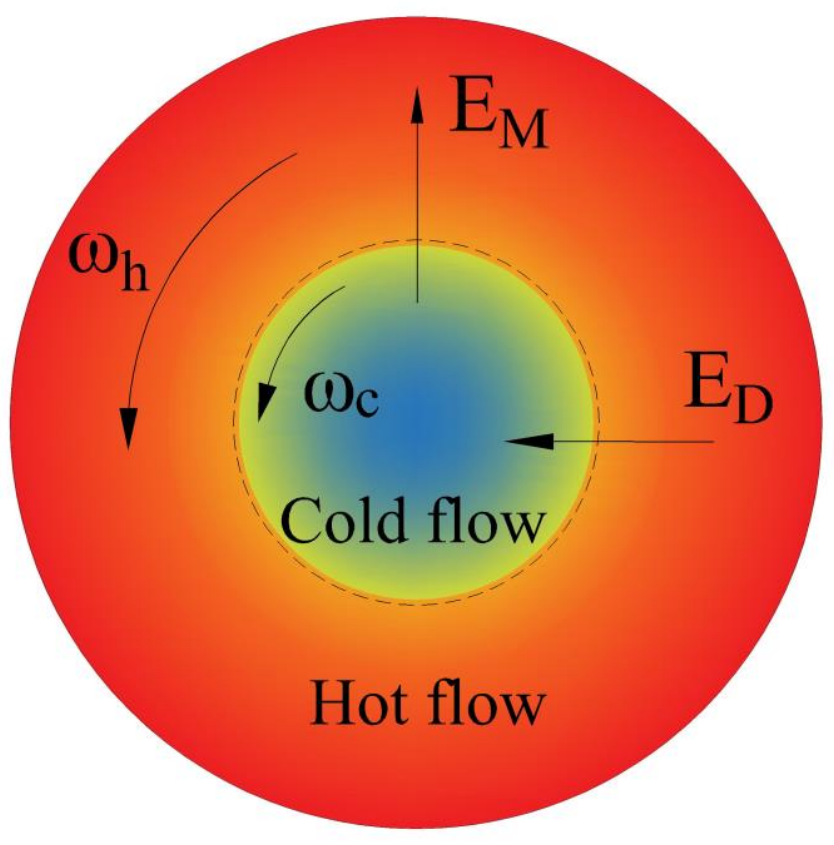

Fig.4 The diagram of the viscous-shear theory

Since the kinetic energy gained by the periphery gas is greater than the internal energy lost, the temperature of periphery gas will be higher, while the temperature of the internal gas will be lower. Fulton asserted the relationship between the maximum temperature difference and the Prandtl number ${ }^{57}$ :

$$
\frac{\Delta T_{c, \max }}{\Delta T_{i s}}=1-\frac{1}{2 P_{r}}
$$


where $\Delta T_{\mathrm{c}, \max }$ is the maximum temperature difference $\left(=T_{\mathrm{in}}-T_{\mathrm{c}}\right), \mathrm{T}_{\mathrm{c}}$ is the temperature of cold orifice, $\Delta \mathrm{T}_{\text {is }}$ is calculated based on an assumption of an isentropic expansion process.

$$
\Delta T_{\text {is }}=T_{\text {in }}\left(1-\left(\frac{p_{c}}{p_{\text {in }}}\right)^{(\gamma-1) / \gamma}\right)
$$

where $p_{\mathrm{c}}$ is the pressure of the cold orifice, $p_{\text {in }}$ is the inlet pressure.

$\operatorname{Van}^{58}$ analyzed the temperature separation of the vortex tube based on the extended Bernoulli equation. The existence of the turbulent mixing in the pressure field of the vortex tube was also considered. When the fluid in a section is rotated at the same angular velocity, the mixture of the fluid in the tube is particularly strong, thus, the static temperature difference is not eliminated by the molecular heat conduction.

\subsection{Secondary Flow Theory}

Ahlborn $^{35}$ found that the reflux fluid mass flow at the centre of the tube was larger than that at the cold exit. Thus, Ahlborn presumed a hypothesis that secondary circulation might exist in the vortex tube and the flow direction was different from the primary flow. The schematic reflects in Fig. 5.

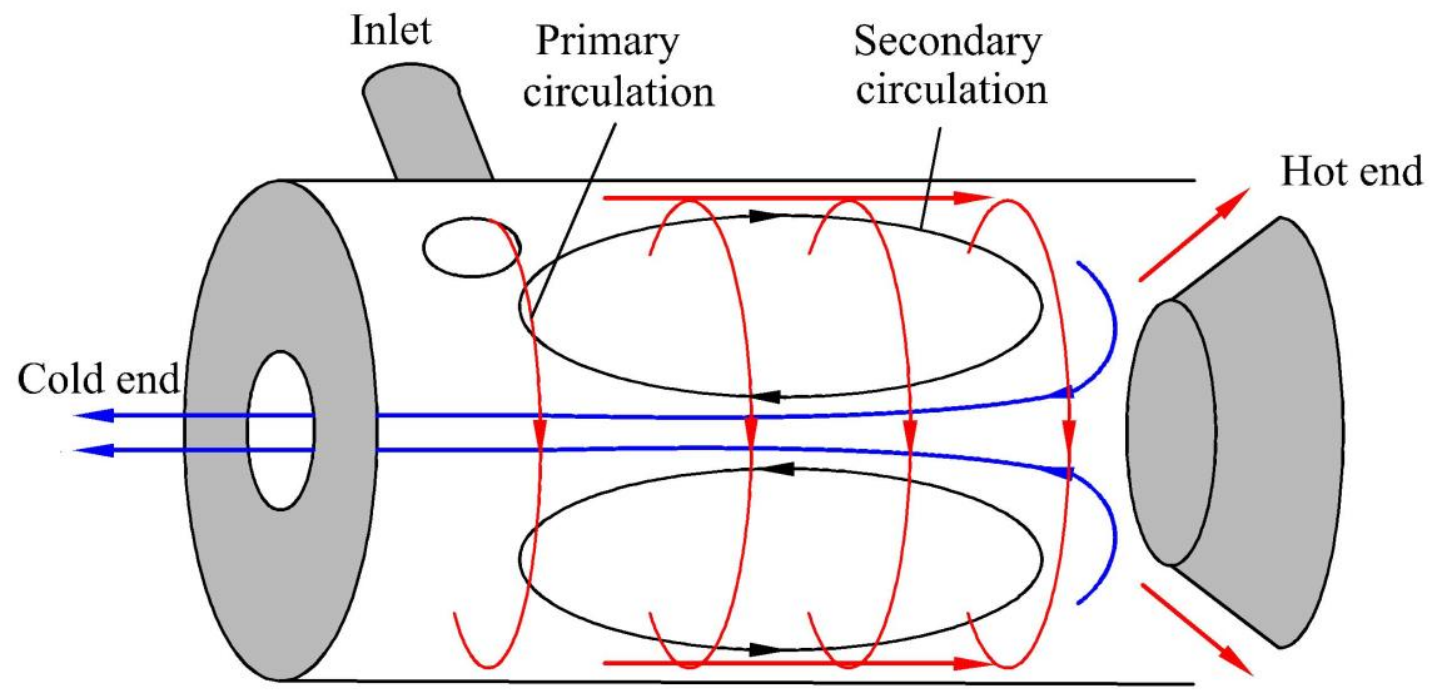

Fig. 5 Schematic cut-away view of vortex tube

Afterwards, Ahlborn ${ }^{59}$ took into account the secondary flow as a classic refrigeration cycle. As can be seen from Fig. 6, compressed gas is injected into the tube, and as the temperature drop due to the expansion, the coldest part in a tube is close to the inlet. The pressure difference can make a part of the gas escape from the cold exit and the other part would mix with the secondary circulation loop. Since the temperature near the inlet nozzle is lower than that at point 1, the gas in the periphery region is heated during the process from point 1 to point 2 . And the secondary circulation loop is an expansion process from point 2 to point 3. During this process, the velocity of the secondary circulation loop maintains high, but the direction changes, meanwhile, the pressure and temperature of the secondary circulation loop 
decrease. The secondary circulation loop begins to mix with the back-flow from the hot-end at point 3 and the temperature is lower than that of back-flow. As a result, during the process from point 3 to point 4 , the heat transfer direction is from the centre to the secondary circulation loop. Due to the internal pressure field, the secondary circulation loop is accelerated. With the accumulation of this mechanical energy, the secondary circulation loop backs to point 1 with the temperature and the pressure increasing. Manimaran ${ }^{60}$ worked with Reynolds stress model for numerical calculation, and the results showed that the axial shear work between the hot and cold vortexes is the main reason for the formation of the secondary flow. Likewise, the research confirmed that the secondary flow could exert a positive effect on the energy separation and the size of the secondary circulation is the main factor affecting the energy separation of the vortex tube rather than the number of the secondary flow.

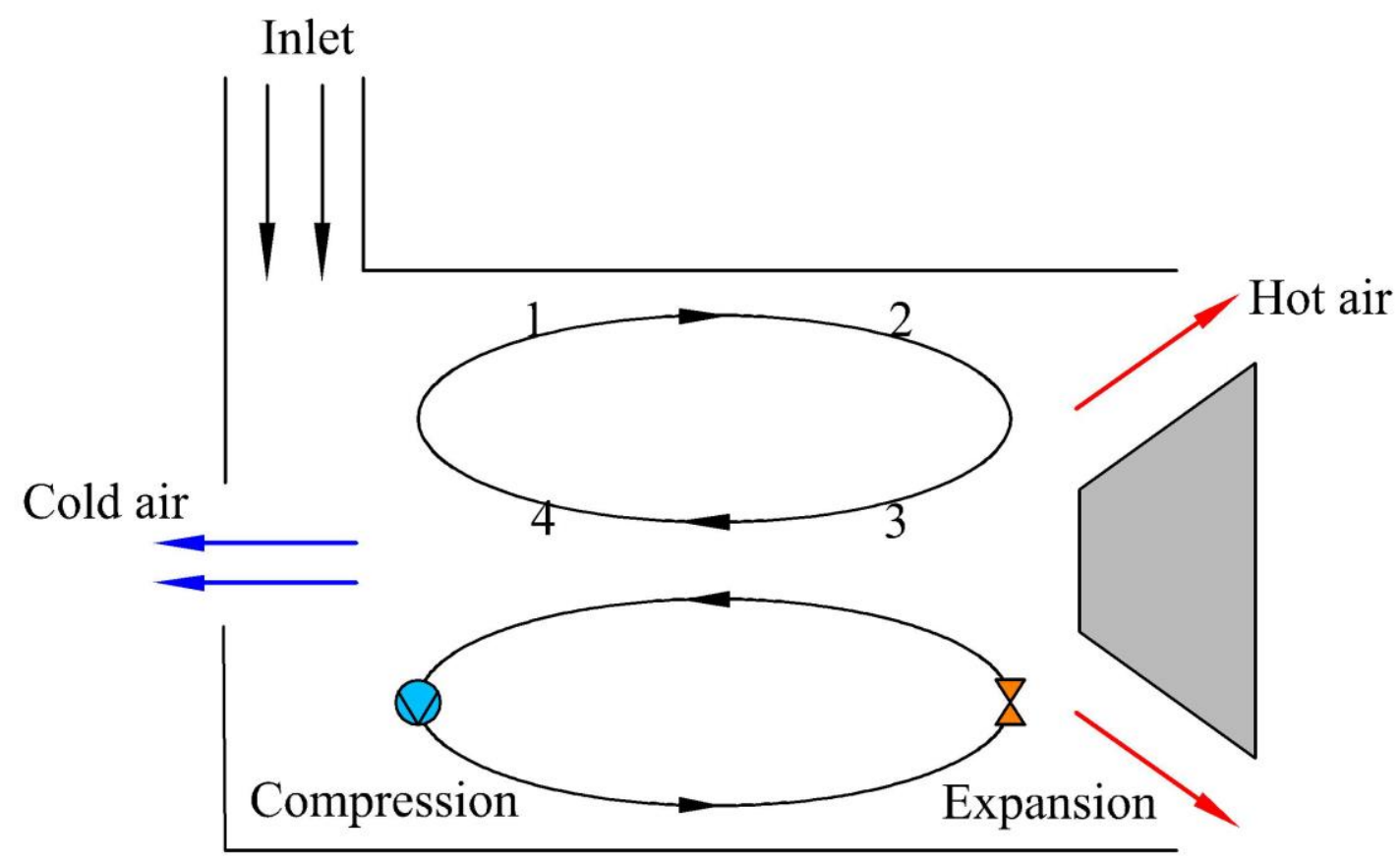

Fig. 6 Secondary circulation flow diagram

However, not all researchers agreed with the secondary flow theory. For example, Behera $^{13}$ concluded that the formation of the secondary circulation is related to the size of the cold exit. When the cold exit is small enough, the secondary circulation loop will form in the vortex tube. With the increase of the cold exit, the secondary circulation will weaken. When the ratio of $d_{\mathrm{c}} \bullet D^{-1}$ is 0.58 , the secondary flow loss occurs. Kandil's study ${ }^{61}$ also revealed the relationship between the secondary flow and cold flow component. When cold mass ratio is less than 0.31, the complete secondary circulation loops are formed. Until the cold mass ratio is greater than 0.74 , the secondary circulation loops disappear.

\subsection{Acoustic streaming theory}

Kurosaka $^{62}$ suggested that the acoustics need to be considered as a factor influencing the temperature separation because of the noise produced during the experiments. Temperature and sound parameters like sound pressure level, noise 
frequency near the entrance were measured. With the increase of the inlet pressure, the sound pressure level and temperature simultaneously change dramatically. It is asserted that the sound flow caused by ordered disturbance could improve the tangential velocity. The flow pattern transfers from Rankine to the forced vortex, the flow temperature distribution changes. Eckert ${ }^{63}$ found that the energy separation effect is even more remarkable when the sound intensity of the vortex tube increases. The study showed that the fluid in tube fluctuates as sound. Besides, the pressure on the pulsation waveform curve is the main reason that leads to the energy separation, while the effect of viscous takes the second. Wisnoea ${ }^{64}$ recorded the sound generated by the vortex tube. Their result summarized that the sound changes mainly occur in the amplitude when the inlet pressure changes. However, the frequency does not change much. The separation chamber depth is the main influencing factor of frequency.

\subsection{Multi-circulation theory}

$\mathrm{Xue}^{34}$ observed the multi-circulation structure by injecting particles in 2011. In the experiment, compressed air was injected into the vortex tube and it was found that the vorticities appeared at the corner of the tube. The angle part of the flow turned back to cold orifice with a lower temperature than the inlet air. The multi-circulations mixed with the component of the cold flow may reduce the cooling effect. The peripheral flow escaped from the hot exit with a higher temperature than the inlet air. And the other parts of the flow were forced back to the cold-end by the plug with increasing swirl velocity. As the rotating radius increases, this part of flow mixed with the peripheral flow. The governing factor of the temperature drop is pressure gradient and the main reason for the temperature rise is partial stagnation and mixing ${ }^{55}$. However, the flow field in the tube varies with the size of the hot-exit, which will discuss it in the next section.

\section{The design criteria of vortex tubes}

It is recognized that many factors could influence the performance of a vortex tube, Hilsch ${ }^{2}$ was the first researcher to investigate the relationship between the performance of a vortex tube and its geometry. Moreover, other researches on improving the temperature separation would be discussed from different aspects in the following section.

\subsection{Types of vortex tube}

According to the flow characteristics, three different types of vortex tubes, namely counter-flow vortex tube, uni-flow vortex tube, and double-circuit vortex tube, are introduced in this paper. The shapes of the counter-flow vortex tube and uni-flow vortex tube have already been introduced. It is generally recognized that the performance of the uni-flow vortex tubes is worse than that with counter-flow vortex tubes. In most cases, the counter-flow vortex tube was selected. In 1996, Piralishvili65 designed a new type of vortex tube, and named it as a double-circuit vortex tube. The structure of this vortex tube is sketched in Fig. 7. In the middle of the plug, there is a hole which is used for injecting the compressed gas. In contrast to a counter-flow 
vortex tube, the double-circuit vortex tube has a better cooling effect ${ }^{66}$. Based on the study of the hot tube cooling ${ }^{67}$, Sadi ${ }^{68}$ improved the design of the vortex tube structure which is demonstrated in Fig.8. The structure named Annular Vortex Tube (AVT) is beneficial to the compression of the hot fluid and the expansion effect of the cold flow in the tube, which not merely ascends the temperature difference between hot and cold exits, but also improves the cooling efficiency.

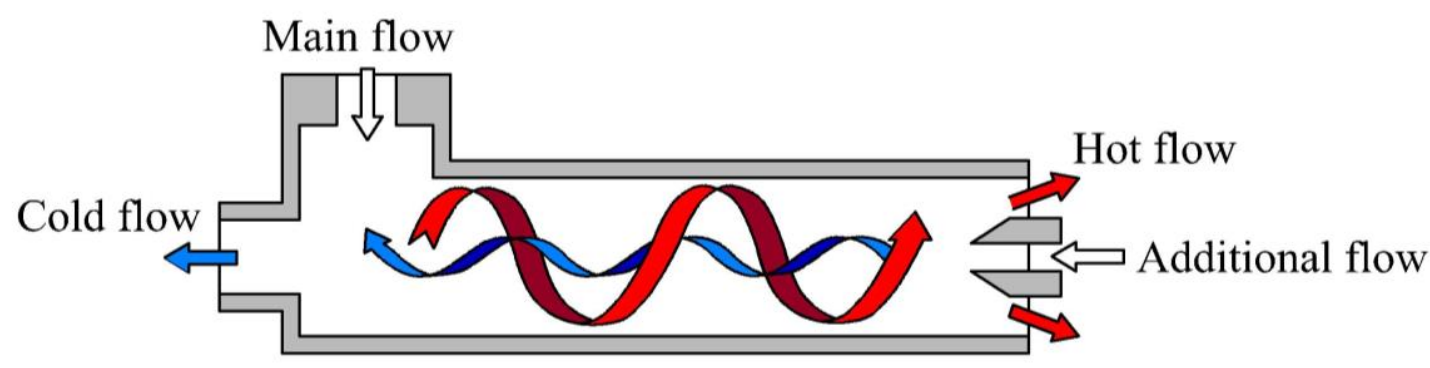

Fig.7 Schematic of the double-circuit vortex tube

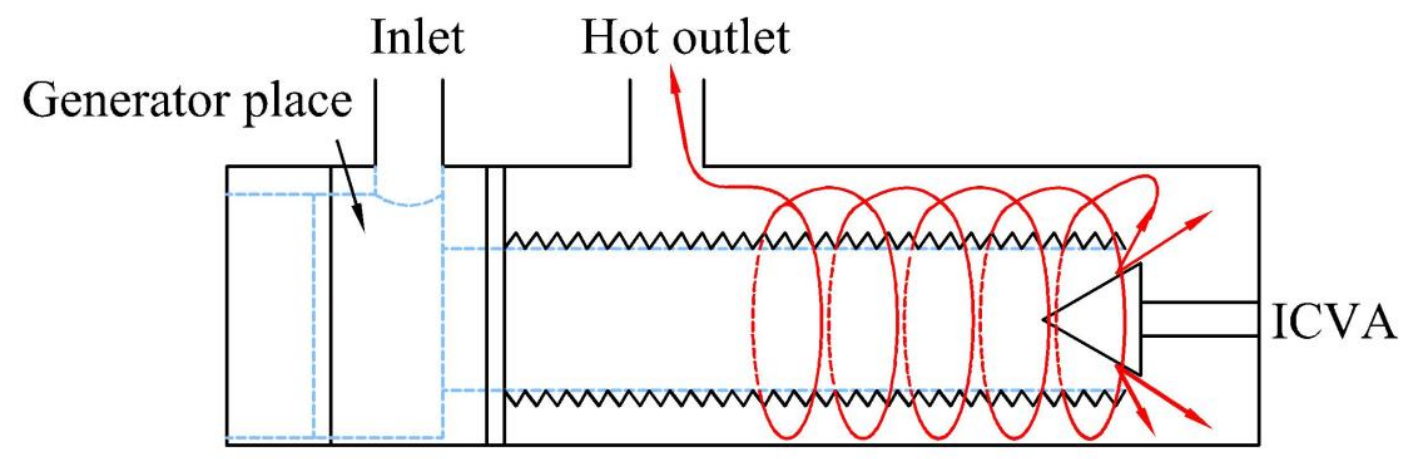

Fig.8 Schematic of the annular vortex tube

\subsection{Tube shape}

The conventional vortex tube is a long tube structure. Paruleker ${ }^{69}$ designed a short conical vortex tube as illustrated by Fig. 9 to reduce the optimum $L / D$ ratio. Research pointed out that the length of the vortex tube could be reduced to $1 / 3$ by varying the conical angle of the vortex tube. Later on, Borisenko ${ }^{70}$ identified that the optimum taper angle for the hot end was $3^{\circ}$.

Bovand $^{71}$ investigated the effect of the tube curvature angles on temperature separation by numerical simulation with the RNG k- $\varepsilon$ model. Their results showed that the vortex tube with bending angle of $150^{\circ}$ could achieve higher performance than that for other curvature angles when used as a refrigerator. But the performance is still not as good as that for straight tube.

Kandil $^{72}$ designed a fins structure for the hot end tube and numerical simulation was carried out by using a k- $\varepsilon$ model, as illustrated in Fig.10. Fins can enhance the external natural convection to cool the tube wall which reduces the central recirculation temperature so that a colder fluid can be obtained at the cold end. 


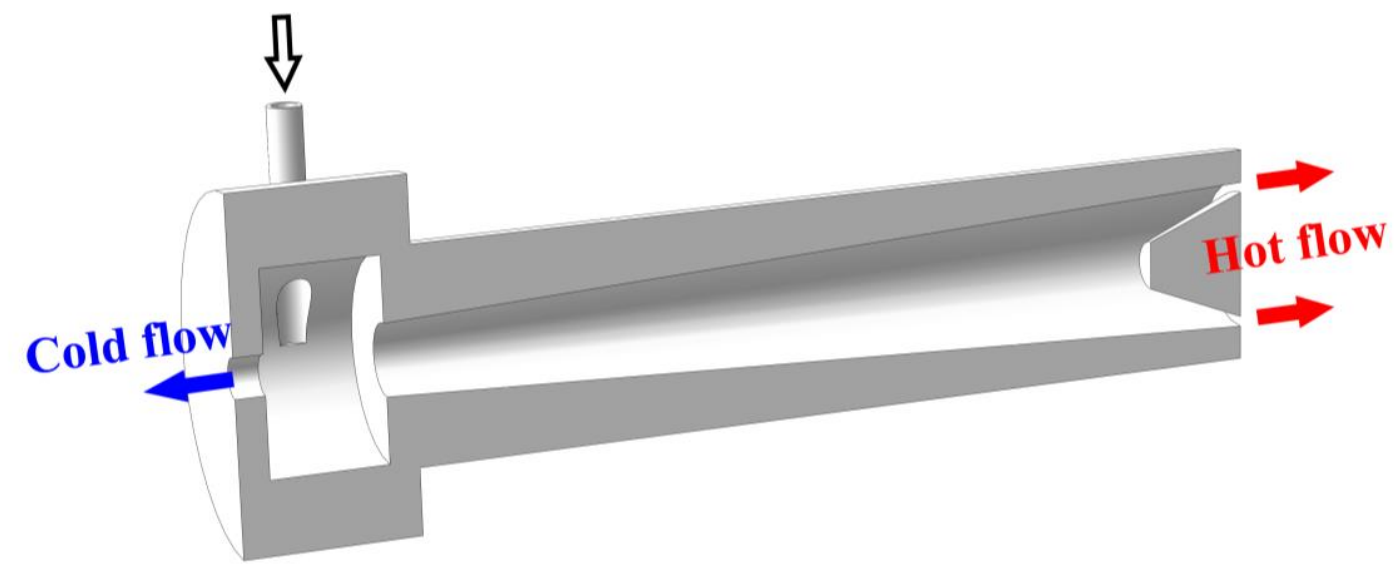

Fig.9 Schematic of the conical vortex tube

\section{Fins}

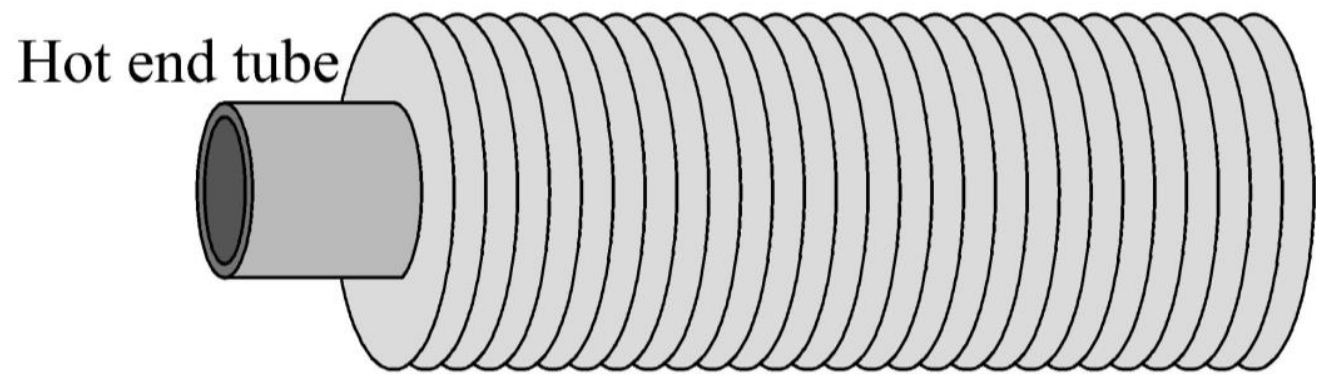

Fig.10 Circular fins used in vortex tube

\subsection{Ratio of tube length over diameter}

It has been studied by many researchers that the length of a vortex tube had an obvious influence on its performance. And several experimental results were summarized by Yilmaz ${ }^{73}$. It was clear that optimum $L / D$ is a function of geometrical and operating parameters, which means the vortex tube has a critical length. When $L / D>45, L / D$ will have no effect on the performance anymore, as demonstrated in Fig. $11^{74}$. For $L / D=10$, temperature separation phenomenon is more unremarkable than others. 


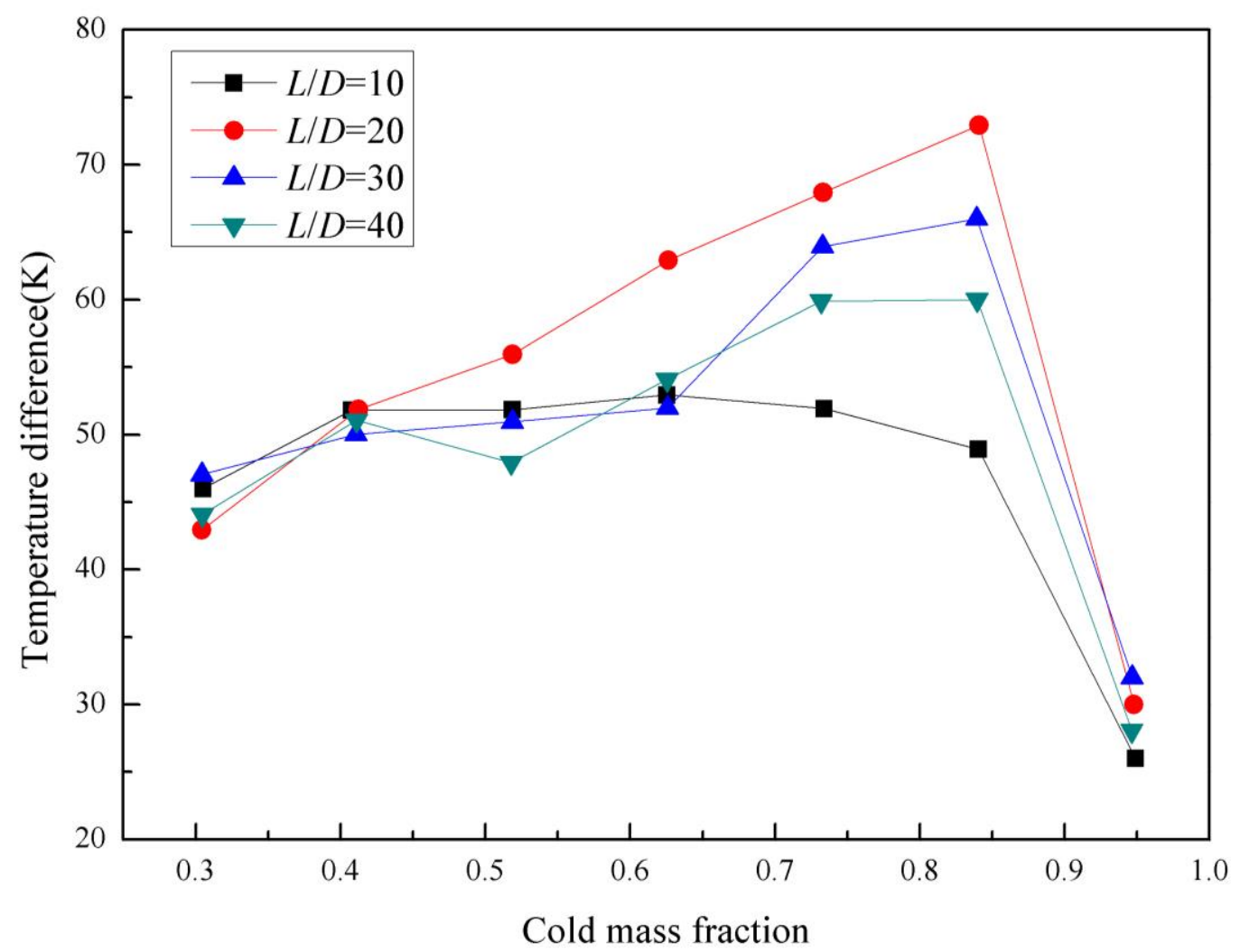

Fig.11 Effect of $L / D$ on temperature difference for various cold mass fractions

Noted that the diameter of the vortex tube affects the flow rate as well as the performance of the vortex tube. In general, a vortex tube with a smaller diameter has a better energy separation. From the plot of $L / D$, a critical diameter exists. If the vortex tube diameter is too small or too large will weaken the temperature separation ${ }^{73}$.

\subsection{Cold orifice}

In 1955, Westley stated the optimized relationship among the injection area, the inlet pressure, the cold orifice and the vortex tube cross-sectional area. The relationship is shown as follows ${ }^{39}$ :

$$
\begin{gathered}
\frac{A_{\text {in }}}{A_{t}}=0.156+\frac{0.176}{\tau_{\mathrm{p}}} \\
A_{c} / A_{t}=0.167 \\
\tau_{\mathrm{p}}=\frac{p_{\text {in }}}{p_{c}}=7.5
\end{gathered}
$$

where $A_{\mathrm{c}}$ is the cross-sectional area of the cold orifice, $A_{\mathrm{t}}$ the vortex tube cross-sectional area, $p_{\text {in }}$ is the inlet pressure and $p_{\mathrm{c}}$ is the cold exit pressure.

It was reported that the dimensionless cold orifice diameter should be in the range of $0.4<d_{\mathrm{c}} / D<0.6$. The research of Pourmahmoud ${ }^{75}$ and Behera ${ }^{13}$ obtained a similar conclusion. Mahmood ${ }^{76}$ conducted an experiment which showed that the cold orifice angle will also affect the flow pattern of the vortex tube. For the cold orifice angle of 
$4.1^{\circ}$, the best energy separation effect is achieved.

\subsection{Nozzle}

The inlet nozzle is an important component of the vortex tube. In order to get the optimal performance, the pressure loss over the inlet nozzle should be small or the Mach number at the outlet of inlet nozzle should be equal to 1, and the momentum flow at the outlet should be large ${ }^{39}$. The shape and number of the vortex tube could influence the performance of the vortex tubes.

\subsubsection{Number of nozzles}

Many researchers discussed the relationship between the number of nozzles and the performance of the vortex tube. Reynolds ${ }^{39}$ suggested that the inlet nozzle should be in the form of slots and more slots could make the vortex tube achieve a better performance. Shamsoddini ${ }^{77}$ investigated the effect of the straight nozzles number ( 2 , $3,4,6,8$ nozzles) on the power of cooling of a vortex tube by 3D numerical fluid dynamic method. The RNG k- $\varepsilon$ model was employed and the simulation results were validated by available published results. It was evidenced that the increase of the number of the nozzles could enhance the cooling capacity significantly while the temperature of the cold outlet decreases moderately. Promvonge and Eiamsa-ard ${ }^{78,79}$ experimentally studied the temperature separation in the vortex tube with 1 to 4 nozzles whose inlet shaped as a snail and drew the same conclusion with Shamsoddini.

\subsubsection{Profile of nozzle}

The shape of the nozzle is considered as a factor to improve the performance of the vortex tube as well. Vortex tubes are usually circular nozzles. Numerical analysis has been carried out on different types of nozzles to achieve the optimum profile of the inlet nozzle by Behera ${ }^{13}$. After comparison of the total temperature difference between the cold exit and hot exit for different nozzle configurations (convergent, circular helical, rectangular helical, straight), it was concluded that the swirl velocity attained by circular and rectangular helical single nozzles are prominently lower than conical nozzles and the total temperature difference bacame smaller. Rafiee ${ }^{80}$ experimentally studied the effect of the convergence ratio on the nozzle in the range of 1 to 2.85. As revealed by Fig. 12, there is an optimum ratio between 1.29 and 1.9 to obtain the highest temperature difference. Parulekar ${ }^{68}$ proposed that the nozzle should be designed in the shape of the Archimedian spiral and the cross section should be slotted. To improve the energy separate efficiency of the vortex tubes, a new nozzle with equal gradients of Mach number gradient and intake flow passage with equal flow velocity were designed by $\mathrm{Wu}$ et $\mathrm{al}^{85}$. A comparison result between various nozzles on cooling effects (nozzle designed by $\mathrm{Wu}$, nozzle of Archimedian spiral, nozzle of normal rectangle cross section) can be seen in Fig. 13. It was indicated that the nozzle designed by $\mathrm{Wu}$ has better performance in temperature separation than that of other nozzles.

The effect of the nozzle diameter on the vortex tube performance has been studied by many researchers. The results summarized by Yilmaz et $\mathrm{al}^{73}$ reported that increasing nozzle diameter could improve the performance generally. The optimum 
nozzle diameter was about $0.25 d_{\mathrm{vt}}$.

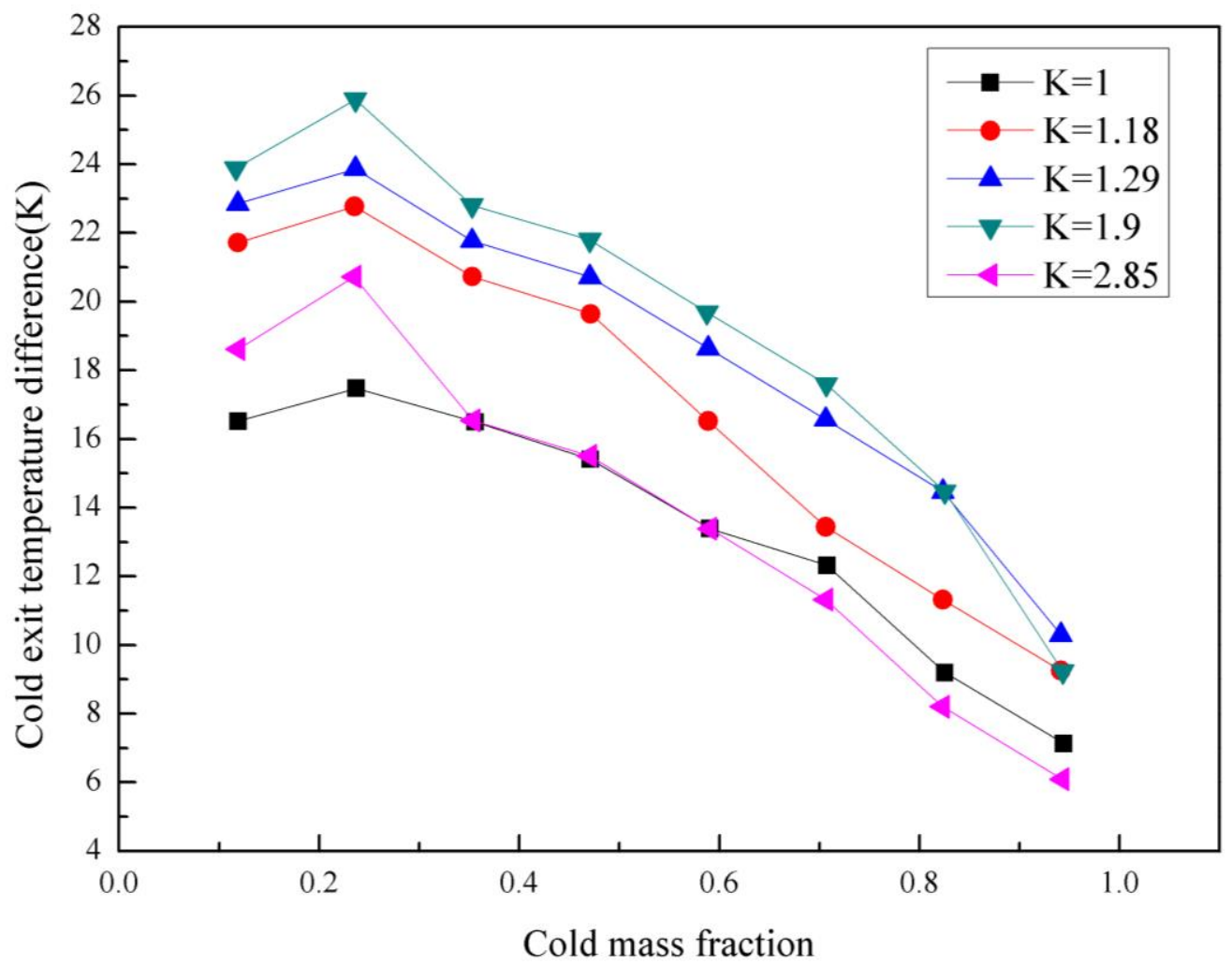

Fig.12 Influence of the convergence ratio of nozzle on the cold temperature difference

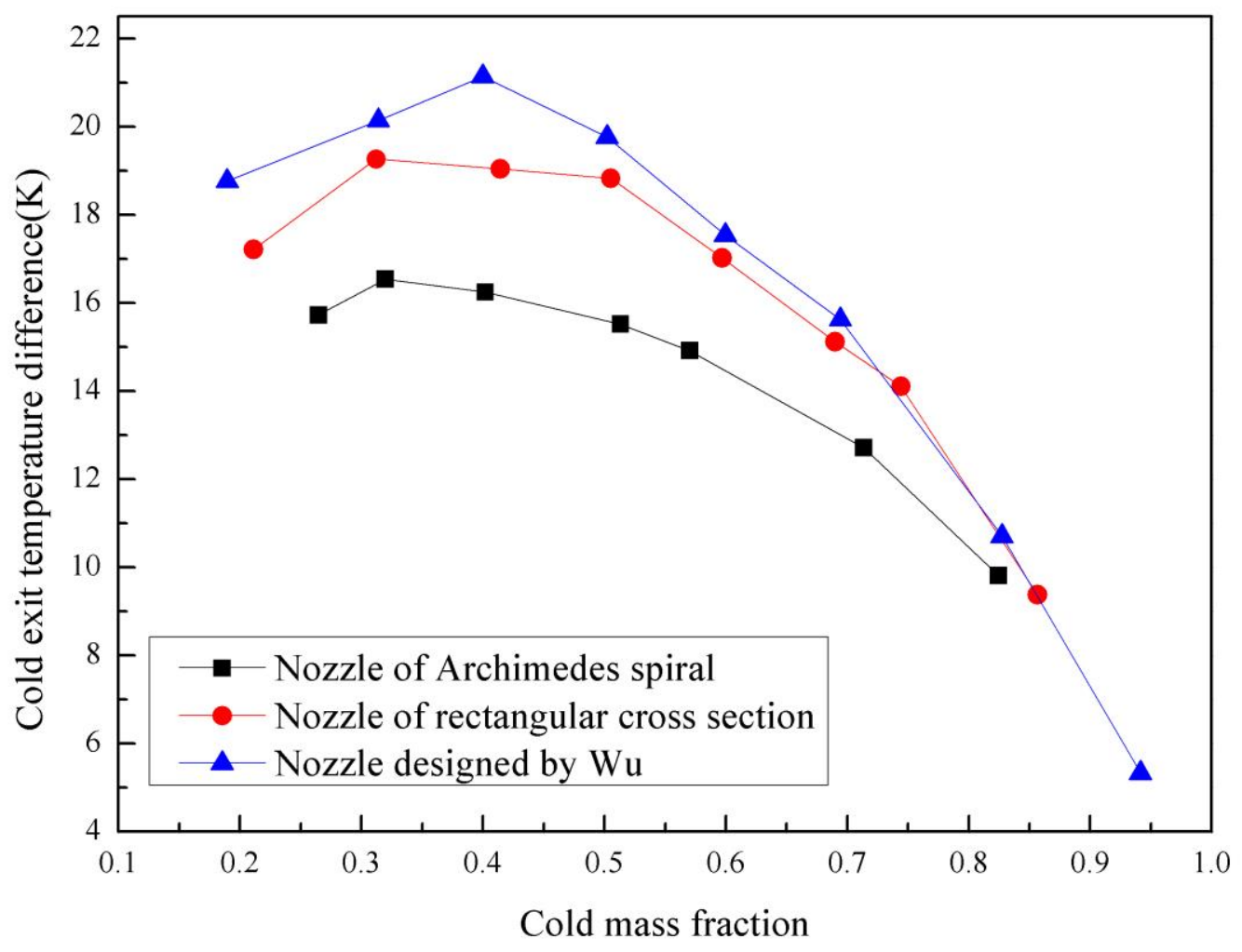

a) Influence of various nozzle on cooling effects 


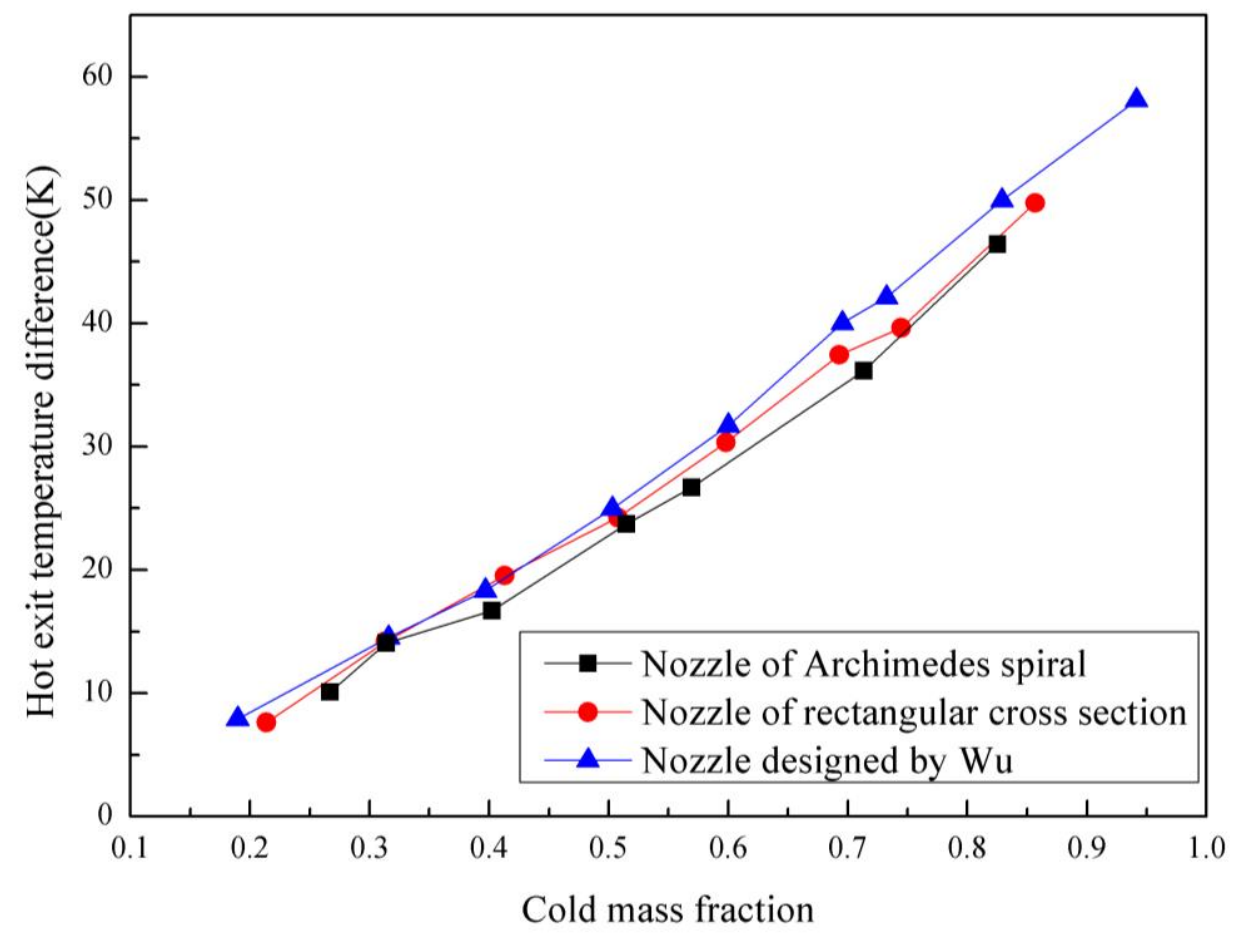

b) Influence of various nozzle on heating effects

Fig.13 Influence of various nozzles on temperature separation

\subsection{Control valve}

As previously mentioned, the size of the hot exit could lead to the change of the flow field. Xue ${ }^{55}$ discussed the flow structure with the control valve at different positions in the vortex tube. An interesting phenomenon is that if the hot exit is relatively large (i.e., the valve is far away from the exit), there will be no backflow in the tube. Due to the strong centrifugal force in the tube, a low pressure region is formed near the cold end so that the ambient air is sucked into the tube through the cold exit. All injected flow will escape from the hot exit. The flow structure is outlined in Fig. 14. When the plug is close to the hot exit, some gas is forced back by the plug, and discharged from the cold exit. If the hot exit area keeps reducing, the vortex tube will generate more cold flow and less hot flow, also the suction at the cold end will not be observed. As far as the hot exit is blocked, all the injected gas left out of the cold exit. Owing to the mixing of the cold flow and the hot flow, the temperature drop of tube is not striking.

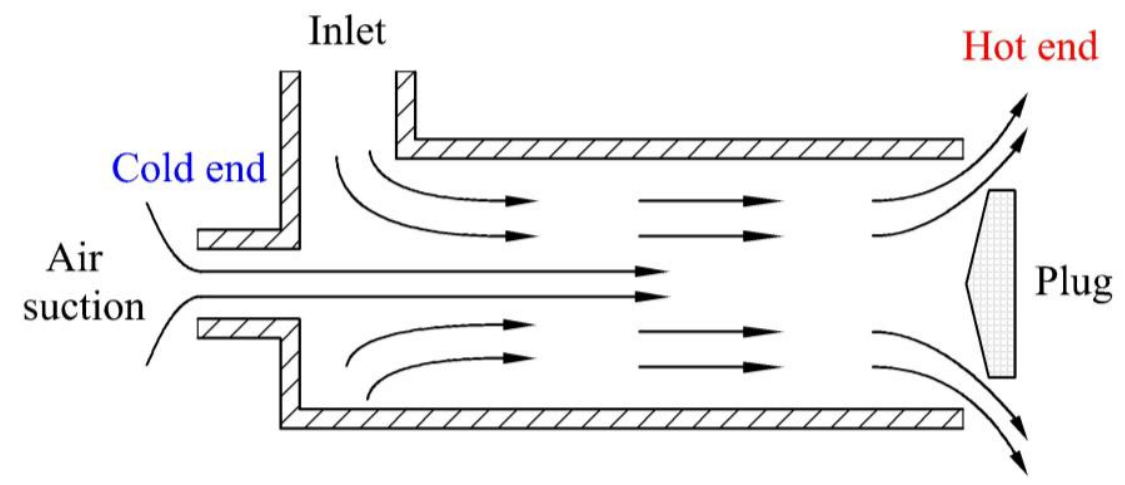

Fig.14 Flow structure in a vortex tube 
The control valve is capable to adjust the cold fluid fraction by changing the position. Additionally, the control valve affects the refrigeration performance. $\mathrm{Gao}^{39}$ carried out an experimental study with three different kinds of hot end plug: spherical, plate-shaped and cone-shaped plug. The schematic drawing of the hot-end plugs is presented in Fig. 15. It pointed out that maximum temperature difference is obtained with the plug (c); the plug (b) has the smallest temperature difference. Rafiee ${ }^{81}$ studied four types of hot valves namely plate, spherical, cone and truncated cone. The simulation results showed that the valve shape directly affects the distribution of the flow field in the vortex tube. The vortex tube under the control of the truncated cone type valve has the minimum distance between stagnation point and the hot valve as well as maximum axial and tangential velocities, which make a best cooling effect for these four type valves.

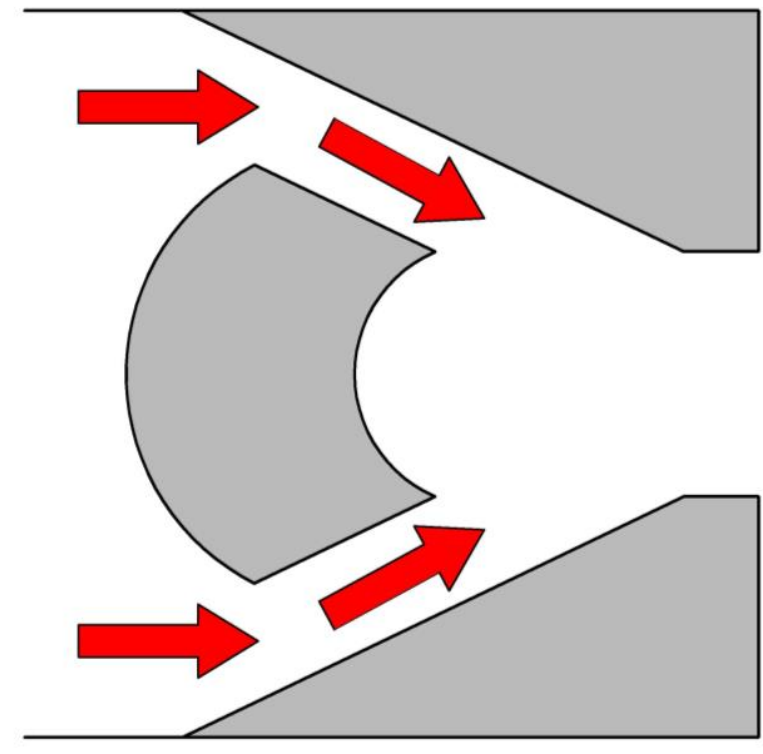

(a) Spherical

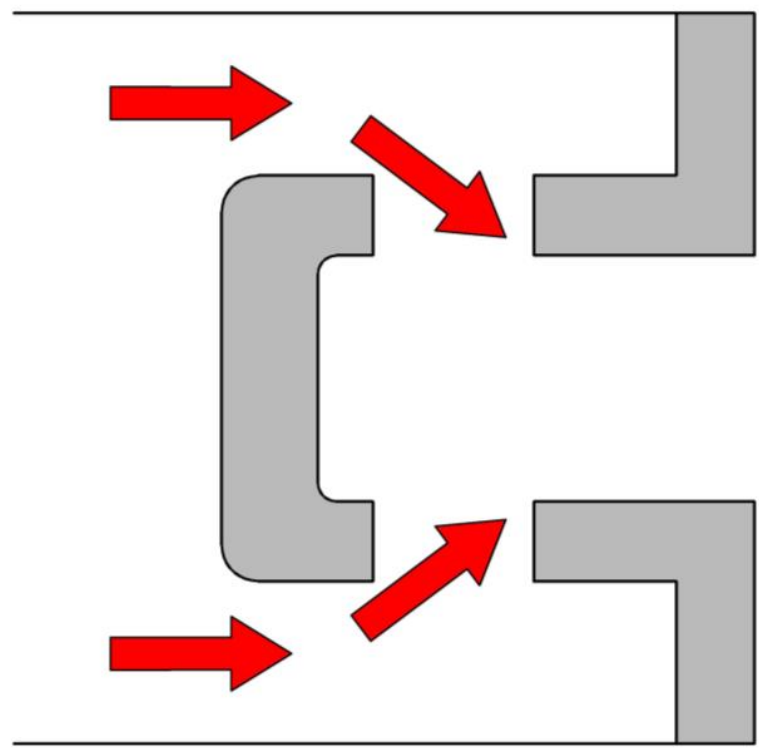

(b) Plate-shaped 


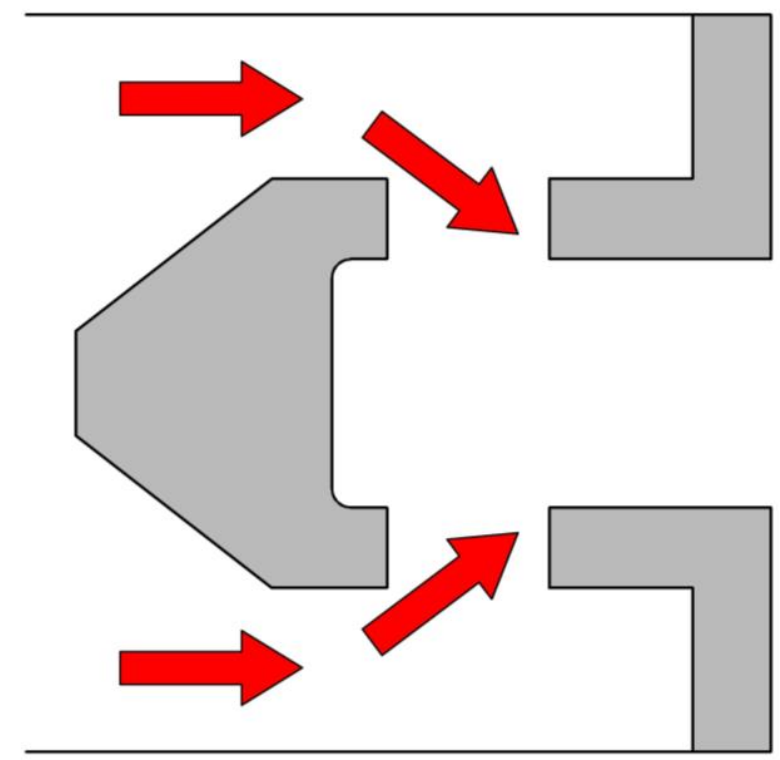

(c) Cone-shaped

Fig. 15 the hot-end plug used by Gao

Markal and Aydin ${ }^{82}$ used four conical valves with different angles, i.e. $30^{\circ}, 45^{\circ}$, $60^{\circ}$ and $75^{\circ}$, disclosed that the conical valve with smaller angle could lead to a better performance of the vortex tube, especially for the small $L / D$ vortex tube.

\subsection{Diffuser}

Diffuser was proposed by Grodzovskii in $1954^{39}$. Diffuser is a kind of vortex stopper to block the vortex motion. Studies seemed to support that placing the diffuser before the hot end contributes to reduce the viscous flow loss and velocity loss. In this case, the diffuser becomes an crucial improvement in the design of the vortex tube ${ }^{83}$.

Hamdan $^{84}$ et al. investigated the effects of the vortex tube under different locations of diffuser (near the inlet, in the middle of tube, near the hot exit). It was revealed that the diffuser location has a direct effect on the performance of the vortex tube: only if the diffuser is close to the hot end, the vortex tube achieves a better cooling. $\mathrm{Wu}^{85}$ et al. designed a new style of diffuser, and installed it in front of the control valve aiming at decreasing the speed of the peripheral fluid to zero and greatly reducing the ratio of length to diameter. It showed that the cooling effect of the vortex tube with diffuser is up to $5^{\circ} \mathrm{C}$ lower than the one without diffuser.

\subsection{Type of gas}

Thakare and Parekh ${ }^{86}$ conducted experiments with different individual and compound gases (Helium, Nitrogen, Oxygen, Hydrogen, Air, $\mathrm{CO}_{2}, \mathrm{H}_{2} \mathrm{O}$ vapour, $\mathrm{CH}_{4}$ ) as the working fluid. They stated that the energy separation effect will be enhanced with the increase of the thermal diffusivity and thermal conductivity of gas for both individual and compound gases. But $\mathrm{H}_{2}$ is the only exception for its high specific heat. The change of the Prandtl number does not show any conclusive evidence about the contribution to the energy separation. Some scholars took hydro fluorocarbons as research objects. Wu selected $\mathrm{R} 744, \mathrm{R} 32$ and $\mathrm{R} 134 \mathrm{a}$ as the working fluid in the 
numerical simulation ${ }^{87}$. The working medium selection of Han included R728, R744, R32, R22, R161 and R134a. The properties of the working medium, such as dynamic viscosity and thermal conductivity, are considered and it was found that they played a remarkable role in the process of energy separation. In addition, the throttling effect of the fluid itself also affects the whole process ${ }^{88}$.

Inlet pressure is another factor that can impact on the performance of the vortex tube $^{89}$. Kurmaci ${ }^{90}$ reported that increasing the inlet pressure could lead to a larger temperature difference between the hot and cold exit. Rafiee ${ }^{80}$, Thakare $^{91}$ and Aydin ${ }^{4}$ obtained the same conclusion. Whereas some other researchers expressed different opinions. They stated that the temperature separation was a function of normalized pressure drop between the inlet and cold end of the vortex tube rather than the inlet pressure. Gulyaev ${ }^{92}$ found that the relationship between the inlet temperature and the cold gas temperature for a given $p_{\mathrm{in} /} p_{\mathrm{c}}$ and cold fraction as expressed in Eq.(8).

$$
\frac{T_{i n}-T_{c}}{T_{\text {in }}}=\text { constant }
$$

Yilmaz et al. ${ }^{73}$ similarly summarized that the inlet temperature had little effect on the temperature separation.

\section{Application of a vortex tube}

The vortex tube has wide application in the field of industry and scientific research. Burno ${ }^{93}$ made statistics on the application of the vortex tube, which was widely used in the field of temperature control at that time.

\subsection{Cooling and heating}

At present, the application of the vortex tube is mainly concentrated in the field of refrigeration and heating. Working in a timely manner without refrigerant, a unique advantage in some occasions, makes vortex tube widely used in industrial electronics cooling, machining cooling, self-propelled systems for hot climate, transport of vegetables and fruit etc ${ }^{23,94}$.

As the role of machining is being gradually important in modern mechanical manufacturing, the high temperature of the tool surface produced by friction during the fast cutting process affects the working efficiency of tool surface. Reasonable cooling measures can improve the service life of the machining tool and ensure machining quality ${ }^{95-97}$. Coolant fluid is used for cooling the cutting tool in traditional method. However, most of the coolant contains additives like phosphorus and sulfur which are unfriendly to the environment. When heating coolant fluid, it will be evaporated into gas easily, which is harmful to the operator ${ }^{98}$. The deployment of the tool costs accounts for about $2 \sim 4 \%$ of the total cost of machining. In comparison, cooling lubricant counts for approximately $7 \sim 17 \%{ }^{99}$. Thus, using a drying cutting could reduce the cost in disposal and cleaning of chips. The comparisons of the dry cutting and traditional cutting on cutting force, cutting temperature, tool wear, surface roughness and residual stress were summarized by Cong et $\mathrm{al}^{99}$. It has been observed that the vortex tube could provide cooling, while it is usually less effective than the coolant fluid in reducing cutting force, temperature, tool wear, and surface roughness. 
With the development of the mining technology and economy, deep mining has become a potential. At the same time, mine heat harm became a serious problem. Using the traditional method to reduce the temperature in the well requires a large amount of energy consumption ${ }^{100}$. On the contrary, there are several advantages of using vortex tube for cooling the well: a) make the best use of a large number of compressed gas underground; b) simple structure, easy operation and maintenance; c) it is the real way of green refrigeration by saving energy as well as avoiding the greenhouse gas emissions. Similarly, Wang et al. designed a vortex tube freezer which used in the mine ${ }^{101}$.

It is necessary to bring the pressure down to a safe range before using the natural gas. The decompression process of high pressure natural gas is similar to adiabatic expansion. The steam in the natural gas may condense into the ice during these processes, which could result in the pipe blockage. The VPGH (Vortex Pilot Gas Heater) was designed to solve this problem ${ }^{102}$. The operating principle of VPGH is displayed in Fig. $16^{103}$. Hot flow in the periphery of the vortex tube was used to preheat gas. The driving force of the vortex tube is the pressure differential available between the vortex tube's inlet and outlet. Although the cost is high, the unique advantages of the vortex tube make the heating in a better economic benefit ${ }^{104}$.

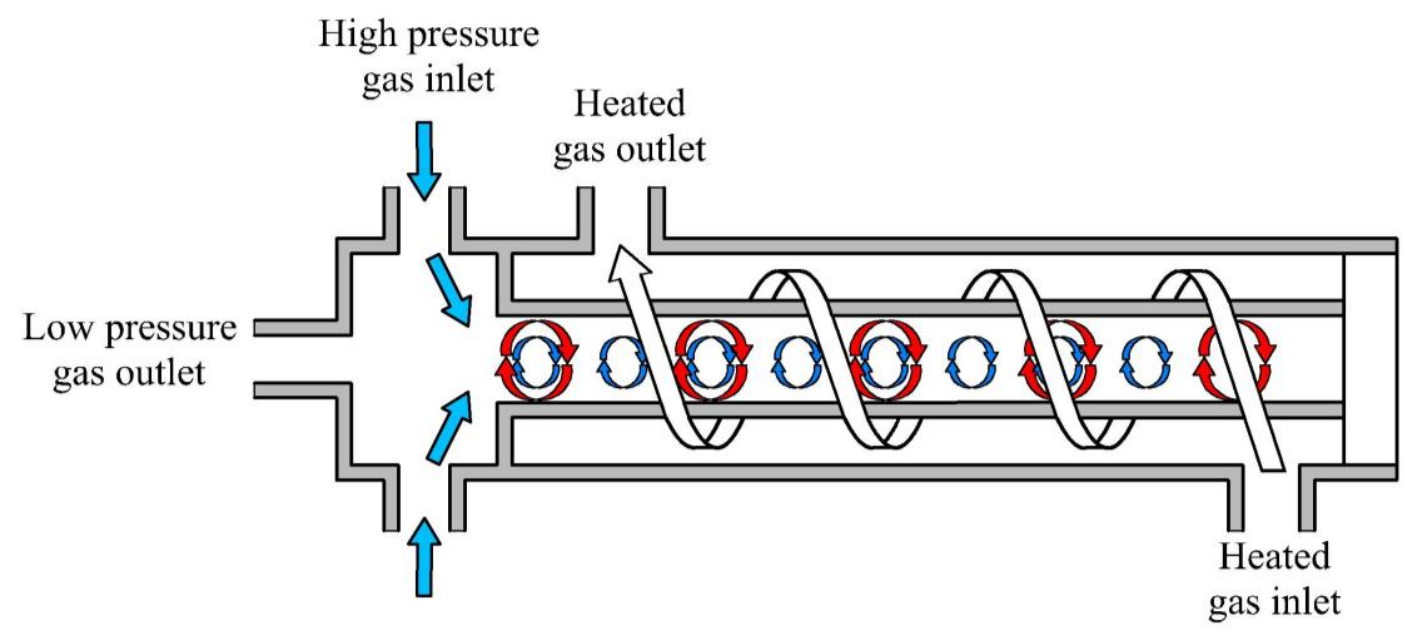

Fig.16 Schematic diagram of vortex tube heater

\subsection{Separation of mixtures}

It is found that the velocity of the working fluid in the vortex tube is very high, and the gas speed in the center can reach $10^{6} \mathrm{rpm}$. Therefore, the vortex tube could also be used for mixture separation. The gas mixture (such as oxygen and nitrogen, oxygen and carbon dioxide) separation experiments using the vortex tube were carried out by Linderstrom-Lang ${ }^{105}$. The results showed that the relatively larger molecular mass of particles stayed in the tube periphery, and the quality of the smaller particles was concentrated in the centre of the tube after separation. Because of the low temperature in the centre of the tube, the gas in this position is easily condensed and liquefied $^{15,106}$. Due to the difference in density between liquid and gas, the liquid will be thrown into the wall by centrifugal action. In order to prevent the liquid regasification caused by the high temperature of the tube wall, the condensate should 
be removed in the process of the separation, the improved structure vortex tube is described in Fig. $17^{107}$. Yun ${ }^{108}$ conducted a feasibility study on the separation of air and carbon dioxide in the vortex tube. It was found that the comparability between the influence of the cold flow ratio on the gas separation as well as the temperature at the cold end. Besides, the separation rate increases when the imported carbon dioxide content changes from $8 \%$ to $16 \%$.

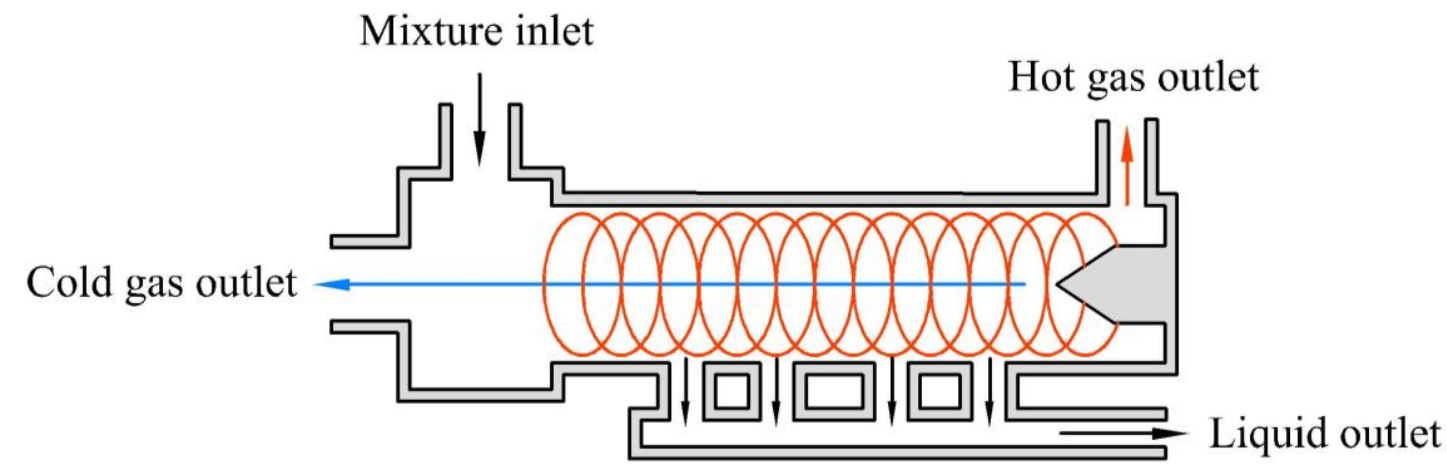

Fig.17 Vortex tube liquid separator

Burger ${ }^{109}$ compared the separation of several different methods to investigate the application of the isotope separation in the vortex tube. It has been pointed out that the method of the electromagnetic isotope separation needs high energy consumption but still the separation effect is not good enough. By contrast, Laser isotope separation method has opposite characteristics. Neverthless, hardware is complex and needs special materials, which is difficult to practice. The centrifugal separator applied to the separation of the particles whose diameter between 1 10 $\mu \mathrm{m}$ showed a good effect. If the particle diameter is less than $1 \mu \mathrm{m}$, the separation effect would decrease greatly. The isotope separation method of the vortex tube could overcome this shortcoming.

In the mining industry, a large amount of methane gas generates during the production, which brings a huge risk to safe production. There are two traditional methods to solve this issue: one is the methane emission in the mine which requires a large amount of capital; the other one is blowing large quantity of air into the mine to dilute the concentration of methane. Both methods will bring an adverse impact on the environment. Mohammadi and Farhadi ${ }^{110}$ conducted an experiment on nitrogen and methane mixture gas separation with vortex tube, their results revealed that this method is capable of collecting methane mixture gas. If the technology is applied to mine production, not only the cost can be saved, but also the methane is collected for the power generation, which will achieve greater economic benefits.

In the 1950s and 1960s, researchers started to focus on evaluating the use of vortex tubes in a gaseous fission rocket concept. Air separation for in-flight oxygen collection was listed in the program paper of NASA Langley's systems analysis office $^{111}$. Following is a briefly describing for the process of gas separation by vortex tube. Air was cooled to the saturation line, partially condensed, and passed through inlet nozzles. The temperature separation of the mixture was accomplished in the chamber. The liquid was thrown to the wall of vortex tube because of the centrifugal force and follows to the hot-exit along the wall. More nitrogen was heated from the 
film near the wall and joined the backflow. From the back flow, oxygen was condensed into liquid, and moved to hot-end. The nitrogen enriched flow left the vortex tube from cold-end. Most of the oxygen concentrations achieved were in the range of $30 \%$ to $40 \%$ with the maximum concentration of oxygen recorded at $58 \%{ }^{27}$.

\section{Conclusions}

Though the structure of the vortex tube is compact, the process of energy separation inside is quite complex. Temperature separation in the vortex tube appears to involve a number of different factors, and it is important to explore the key factors. The theories listed in this article are based on the experiments, but still there is no clear theory to explain the phenomenon completely. The theories mentioned above give hints for further investigations, at the same time provides the directions of theoretical research.

Conclusions can be drawn from a review of various studies: a number of factors have great influence on the performance of vortex tube, such as the ratio of length to diameter, the number of inlet nozzle, the profile of nozzle, the diffuser the inlet pressure and the cold mass fraction. Some factors affecting the performance of the vortex tube are not apparent, like the shape of the hot-end plug, the inlet temperature. All of this information is helpful to design the efficient vortex tube.

Due to its low refrigeration efficiency and refrigerating capacity, the application of the vortex tubes has not been pay much attention to. However, its characteristics still make it play role in some fields. With further research and practice, the application of the vortex tube will be more extensive.

\section{References}

1 GJ, R. Experiments on expansion in a vortex with simultaneous exhaust of hot air and cold air. Phys Radium, 112-114 (1933).

2 Hilsch, R. The Use of the Expansion of Gases in a Centrifugal Field as Cooling Process. Review of Scientific Instruments 18, 108, doi:10.1063/1.1740893 (1947).

3 Smith, J. L. An Experimental Study of the Vortex in the Cyclone Separator. Journal of Fluids Engineering 84, 602-608 (1962).

4 Aydin, O. \& Baki, M. An experimental study on the design parameters of a counterflow vortex tube. Energy 31, 2763-2772, doi:10.1016/j.energy.2005.11.017 (2006).

5 Xue, Y., Arjomandi, M. \& Kelso, R. A critical review of temperature separation in a vortex tube. Experimental Thermal and Fluid Science 34, 1367-1374, doi:10.1016/j.expthermflusci.2010.06.010 (2010).

6 Cao Yong, Liu Jiayong, Gong Maoqiong, et al. An experimental research on the performance of a small flow vortex tube[J]. Journal of Engineering Thermophysics, 2005, 26(1): 14-17.

7 Khazaei, H., Teymourtash, A. R. \& Malek-Jafarian, M. Effects of gas properties and geometrical parameters on performance of a vortex tube. Scientia Iranica 19, 454-462, doi:10.1016/j.scient.2012.03.003 (2012).

8 JI Yubang, WU Yuting, DING Yu, et al. Study of the influence of structural parameters on the vortex tube performance[J]. Journal of Aerospace Power, 2006, 21(1): 88-93 

separation in a vortex tube. International Journal of Refrigeration 55, 93-101, doi:10.1016/j.ijrefrig.2015.03.011 (2015).

Kirmac1, V., Uluer, O. \& Dincer, K. An Experimental Investigation of Performance and Exergy Analysis of a Counterflow Vortex Tube Having Various Nozzle Numbers at Different Inlet Pressures of Air, Oxygen, Nitrogen, and Argon. Journal of Heat Transfer 132, 121701, doi:10.1115/1.4002284 (2010).

11 Pourmahmoud, N., Zadeh, H., Moutaby, O. \& Bramo, A. CFD analysis of helical nozzles effects on the energy separation in a vortex tube. Thermal Science 16, 151-166, doi:10.2298/tsci110531085p (2012).

12 Azarov, A. I. WAYS OF IMPROVING COMMERCIAL VORTEX TUBES Chem Petrol Eng 40, 411-416 (2004).

Behera, U. et al. CFD analysis and experimental investigations towards optimizing the parameters of Ranque-Hilsch vortex tube. International Journal of Heat and Mass Transfer 48, 1961-1973, doi:10.1016/j.ijheatmasstransfer.2004.12.046 (2005).

Dincer, K., Avci, A., Baskaya, S. \& Berber, A. Experimental investigation and exergy analysis of the performance of a counter flow Ranque-Hilsch vortex tube with regard to nozzle cross-section areas. International Journal of Refrigeration 33, 954-962, doi:10.1016/j.ijrefrig.2010.03.009 (2010).

MA Qingfen, ZHANG Yan, QIU Zhonghua \& Shijun, H. Influence of Condensable Gas Component on Energy Separation Efficiency of Vortex Tube. TROPICAL AGRICULTURAL ENGINEERING 34, 52-55 (2010).

Ahlborn, B., Camire J \& JU., K. Low-pressure vortex tubes. Journal of Physics. D: Applied Physics 29, 1469-1472 (1996).

Shannak, B. A. Temperature separation and friction losses in vortex tube. Heat and Mass Transfer 40, 779-785, doi:10.1007/s00231-003-0485-1 (2003).

Pinar AM, Uluer O \& V., K. Optimization of counter flow Ranque-Hilsch vortex tube performance using Taguchi method. International Journal of Refrigeration 32, 1487-1494 (2009).

Korkmaz M, Gumusel L \& B., M. Using artificial neural network for predicting performance of the Ranque-Hilsch vortex tube. International Journal of Refrigeration 35, 1690-1696 (2012).

Dincer, K., Tasdemir, S., Baskaya, S. \& Uysal, B. Z. Modeling of the effects of length to diameter ratio and nozzle number on the performance of counterflow Ranque-Hilsch vortex tubes using artificial neural networks. Applied Thermal Engineering 28, 2380-2390, doi:10.1016/j.applthermaleng.2008.01.016 (2008).

Kocabas, F., Korkmaz, M., Sorgucu, U. \& Donmez, S. Modeling of heating and cooling performance of counter flow type vortex tube by using artificial neural network. International Journal of Refrigeration 33, 963-972, doi:10.1016/j.ijrefrig.2010.02.006 (2010).

Uluer, O., Kırmacı, V. \& Ataş, Ş. Using the artificial neural network model for modeling the performance of the counter flow vortex tube. Expert Systems with Applications 36, 12256-12263, doi:10.1016/j.eswa.2009.04.061 (2009). 2013 Ieee International Electric Machines \& Drives Conference (Iemdc), 456-461 (2013). 
Khodorkov, I. L., Poshernev, N. V. \& Zhidkov, M. A. The vortex tube - A universal device for heating, cooling, cleaning, and drying gases and separating gas mixtures. Chem Petrol Eng+ 39, 409-415, doi:Doi 10.1023/A:1026336813155 (2003).

Balepin V, Petley D, Rosholt D . Progress in Air Separation with the Vortex Tube[M]. NASA Langley Technical Report Server, 1999.

R. Kbnieier, S. Whitney \& Aiusupally, S. Ranque-Hilsch Vortex Tube Thermocycler for DNA amplication. INSTRUMENTATION SCIENCE AND TECHNOLOGY 32, 567-570 (2004). Liu Y F, Geng C J , Jin G Y . Vortex Tube Expansion Transcritical CO2 Heat Pump Cycle[J]. Applied Mechanics and Materials, 2012, 190-191:1340-1344. $\mathrm{Hu}$ Hongtao. Study on performance of micro vortex tube[D]. Dalian: Dalian University of Technology, 2002.

Gutak, A. D. Experimental investigation and industrial application of Ranque-Hilsch vortex tube. International Journal of Refrigeration 49, 93-98, doi:10.1016/j.ijrefrig.2014.09.021 (2015).

Azarov, A. I. Industrial application of multipurpose vortex air coolers, Compressors, Pumps and Refrigeration Technology. Chem Petrol Eng+ 35, 392-395 (1999).

Crocker, A., White, S., Knowlen, C. \& Weimer, R. Experimental Results of a Vortex Tube Air Separator for Advanced Space Transportation. doi:10.2514/6.2003-4451 (2003).

MacGee, J. . Fluid action in the vortex tube. J. ASRE Refrigerating Engng, 974-975 (1950). V. A. Arbuzov, Yu. N. Dubnishchev, A. V. Lebedev, M. Kh. Pravdina \& Yavorski, N. I. Observation of large-scale hydrodynamic structures in a vortex tube and the Ranque effect. American Institute of Physics (1997).

Xue, Y., Arjomandi, M. \& Kelso, R. Visualization of the flow structure in a vortex tube. Experimental Thermal and Fluid Science 35, 1514-1521, doi:10.1016/j.expthermflusci.2011.07.001 (2011).

Boye Ahlbom \& Groves, S. Secondary flow in a vortex tube. Fluid Dynamics Research 21, 73-86 (1997).

Xue Y, Arjomandi M, Kelso R. Experimental study of the flow structure in a counter flow Ranque-Hilsch vortex tube[J]. International Journal of Heat \& Mass Transfer, 2012, 55(21-22):5853-5860.

Wang HF, Li ZF \& XD., L. Comparison of the performance of cobra probe and hotwire in circular cylinder wake. Journal of Experiments in Fluid Mechanics 28, 104-110 (2014).

Gao, C. M., Bosschaart, K. J., Zeegers, J. C. H. \& de Waele, A. T. A. M. Experimental study on a simple Ranque-Hilsch vortex tube. Cryogenics 45, 173-183, doi:10.1016/j.cryogenics.2004.09.004 (2005).

Gao, C. Experimental Study on the Ranque-Hilsch Vortex Tube, Technische Universiteit Eindhoven, 2005.

40 Khait, A. V., Noskov, A. S., Lovtsov, A. V. \& Alekhin, V. N. Semi-empirical turbulence model for numerical simulation of swirled compressible flows observed in Ranque-Hilsch vortex tube. International Journal of Refrigeration 48, 132-141, doi:10.1016/j.ijrefrig.2014.09.006 (2014).

41 Aljuwayhel, N. F., Nellis, G. F. \& Klein, S. A. Parametric and internal study of the vortex tube using a CFD model. International Journal of Refrigeration 28, 442-450, doi:10.1016/j.ijrefrig.2004.04.004 (2005). 
Zhou Shaowei. Investigations into Energy Separation Modeland Numerical simulationof the vortex tube[D], Harbin: Harbin Engineering University, 2007.

43 Saeid, , A., Nader, , P. \& Hasan, S. Numerical study of the temperature separation in the Ranque-Hilsch vortex tube. American Journal of Engineering \& Applied Sciences 1, 181-187 (2008).

Farouk, T. \& Farouk, B. Large eddy simulations of the flow field and temperature separation in the Ranque-Hilsch vortex tube. International Journal of Heat and Mass Transfer 50, 4724-4735, doi:10.1016/j.ijheatmasstransfer.2007.03.048 (2007).

Tian Han, Cui Xiaochao, Meng Wenjun \& Fenglan, C. large eddy simulation of three dimensional flow field in axial flow type vortex tube. Refrigeration 37, 49-58 (2009).

Tanvir Farouka, Bakhtier Farouka \& Gutsol, A. Simulation of gas species and temperature separation in the counter-flow Ranque-Hilsch vortex tube using the large eddy simulation technique. Heat Mass Transfer 52, 3320-3333 (2006).

Eiamsa-ard, S. \& Promvonge, P. Numerical investigation of the thermal separation in a Ranque-Hilsch vortex tube. International Journal of Heat and Mass Transfer 50, 821-832, doi:10.1016/j.ijheatmasstransfer.2006.08.018 (2007).

Baghdad, M., Ouadha, A., Imine, O. \& Addad, Y. Numerical study of energy separation in a vortex tube with different RANS models. International Journal of Thermal Sciences 50, 2377-2385, doi:10.1016/j.ijthermalsci.2011.07.011 (2011).

Zhang B , Guo X, Yang Z . Analysis on the Fluid Flow in Vortex Tube with Vortex Periodical Oscillation Characteristics[J]. International Journal of Heat \& Mass Transfer, 2016, 103:1166-1175.

S. Leibovich, The structure of vortex breakdown, Ann. Rev. Fluid Mech. 10(1978) 221-246. Cao Yong, Qi Yanfeng. The Study on Vortex Tube as a Heat Exchanger[J]. FLUID MACHINERY, 2002, 30(7): 44-46.

Kazantseva, O. V., Piralishvili, S. A. \& Fuzeeva, A. A. Numerical simulation of swirling flows in vortex tubes. High Temp+ 43, 608-613, doi:DOI 10.1007/s10740-005-0102-8 (2005). Kalashnik, M. V. \& Visheratin, K. N. Cyclostrophic adjustment in swirling gas flows and the Ranque-Hilsch vortex tube effect. Journal of Experimental and Theoretical Physics 106, 819-829, doi:10.1134/s1063776108040225 (2008).

Behera, U., Paul, P. J., Dinesh, K. \& Jacob, S. Numerical investigations on flow behaviour and energy separation in Ranque-Hilsch vortex tube. International Journal of Heat and Mass Transfer 51, 6077-6089, doi:10.1016/j.ijheatmasstransfer.2008.03.029 (2008).

Xue, Y., Arjomandi, M. \& Kelso, R. The working principle of a vortex tube. International Journal of Refrigeration 36, 1730-1740, doi:10.1016/j.ijrefrig.2013.04.016 (2013).

R.T.Balmer. Pressure Driven Ranque Hilsch Temperature Separation in Liquids. Fluid Eng, 161-164 (1988).

Fulton, C. D. Ranque's tube. ASRE Refrigerating Engng, 473 - 479 (1950).

DJJ, V. On the theory of the Ranque-Hilsch cooling effect. Applied Scientific Research 3, 174-196 (1952).

Ahlborn, B. K. \& Gordon, J. M. The vortex tube as a classic thermodynamic refrigeration cycle. J Appl Phys 88, 3645-3653, doi:Doi 10.1063/1.1289524 (2000).

R. Manimaran. Computational analysis of flow features and energy separation in a counter-flow vortex tube based on number of inlets. Energy.123(2017)564-578. 
Kandil, H. A. \& Abdelghany, S. T. Computational investigation of different effects on the performance of the Ranque-Hilsch vortex tube. Energy 84, 207-218, doi:10.1016/j.energy.2015.02.089 (2015).

62 KUROSAKA, M. Acoustic streaming in swirling flow and the Ranque-Hilsch (vortex-tube) effect. Fluid Mech 124, 139-172 (1982).

63 E.R.G.Eckert. Energy separation in fluid streams. Heat and Mass Transfer 13, 127-143 (1986).

64 W. Wisnoea, K. M. A. Rahmana, Y. Istihatb, V. D. Natarajan. Thermofluid-Acous tic Analysis of a Ranque-Hilsch Vortex Tube. 3rd International Conference on System-integrated Intelligence: New Challenges for Product and Production Engineerin g, SysInt 2016

Sh. A. Piralishvili \& Polyaev, V. M. Flow and thermodynamic characteristics of energy separation in a double-circuit vortex tube - An experimental investigation. Experimental Thermal and Fluid Science 12, 399-410 (1996).

Alekhin, V., Bianco, V., Khait, A. \& Noskov, A. Numerical investigation of a double-circuit Ranque-Hilsch vortex tube. International Journal of Thermal Sciences 89, 272-282, doi:10.1016/j.ijthermalsci.2014.11.012 (2015).

Eiamsa-ard, S., Wongcharee, K., Promvonge, P.Experimental investigation on energy separation in a counterflow RanqueeHilsch vortex tube: effect of cooling a hot tube. Int. Commun. Heat Mass Transf. 37, 156-162. 2010

Sadi M, Farzaneh-Gord M . Introduction of Annular Vortex Tube and experimental comparison with Ranque-Hilsch Vortex Tube[J]. International Journal of Refrigeration, 2014, 46:142-151.

Parulekar. B. B. The short vortex tube. The Journal of Refrigeration, 74-80 (1961).

A. I. Borisenko, V. A. Safonov \& ., A. I. Y. The effect of geometric parameters on the characteristics of a conical vortex cooling unit. Journal of Engineering Physics and Thermophysics 15, 1158-1162 (1968).

71 Bovand, M., Valipour, M. S., Eiamsa-ard, S. \& Tamayol, A. Numerical analysis for curved vortex tube optimization. International Communications in Heat and Mass Transfer 50, 98-107, doi:10.1016/j.icheatmasstransfer.2013.11.012 (2014).

Kandil H A , Abdelghany S T . Computational investigation of different effects on the performance of the Ranque-Hilsch vortex tube. Energy, 2015, 84(4):207-218. Yilmaz, M., Kaya, M., Karagoz, S. \& Erdogan, S. A review on design criteria for vortex tubes. Heat and Mass Transfer 45, 613-632, doi:10.1007/s00231-008-0447-8 (2008).

74 Markal, B., Aydın, O. Avcı, M. An experimental study on the effect of the valve angle of counter-flow Ranque-Hilsch vortex tubes on thermal energy separation. Experimental Thermal and Fluid Science,34, 966-971(2010).

75 Pourmahmoud;, N., Esmaily;, R. \& Hassanzadeh, A. Experimental Investigation of Diameter of Cold End Orifice Effect in Vortex Tube Journal of Thermophysics and Heat Transfer 29, 629-632 (2015).

76 Farzaneh-Gord M, Sadi M . Improving vortex tube performance based on vortex generator design[J]. Energy, 2014, 72(7):492-500.

77 Shamsoddini, R. \& Nezhad, A. H. Numerical analysis of the effects of nozzles number on the flow and power of cooling of a vortex tube. International Journal of Refrigeration 33, 
774-782, doi:10.1016/j.ijrefrig.2009.12.029 (2010).

Eiamsa-Ard S, Wongcharee K, Promvonge P. Experimental investigation on energy separation in a counter-flow Ranque - Hilsch vortex tube: Effect of cooling a hot tube $\boldsymbol{\Sigma}[\mathrm{J}]$. International Communications in Heat \& Mass Transfer, 2010, 37(2):156-162. Pongjet Promvonge \& Eiamsa-ard, S. Investigation on the Vortex Thermal Separation in a Vortex Tube Refrigerator. Science Asia 31, 215-223 (2005).

Rafiee, S. E. \& Rahimi, M. Experimental study and three-dimensional (3D) computational fluid dynamics (CFD) analysis on the effect of the convergence ratio, pressure inlet and number of nozzle intake on vortex tube performance-Validation and CFD optimization. Energy 63, 195-204, doi:10.1016/j.energy.2013.09.060 (2013).

81 Rafiee S E, Sadeghiazad M M . Experimental and 3D CFD investigation on heat transfer and energy separation inside a counter flow vortex tube using different shapes of hot control valves. Applied Thermal Engineering, 2017, 110:648-664.

Markal, B., Aydin, O. \& Avc1, M. An experimental study on the effect of the valve angle of counter-flow Ranque-Hilsch vortex tubes on thermal energy separation. Experimental Thermal and Fluid Science 34, 966-971, doi:10.1016/j.expthermflusci.2010.02.013 (2010). He Shu et al. Effect of the Rectify on the Energy Separation Performance of the Vortex Tube. Journal of Refrigeration 27, 38-41 (2006).

Hamdan M O , Alawar A, Elnajjar E, et al. Experimental analysis on vortex tube energy separation performance[J]. Heat \& Mass Transfer, 2011.

Wu Y T, Ding Y, Ji Y B, et al. Modification and experimental research on vortex tube[J]. International Journal of Refrigeration, 2007, 30(6):1042-1049.

Thakare, H. R. \& Parekh, A. D. CFD analysis of energy separation of vortex tube employing different gases, turbulence models and discretisation schemes. International Journal of Heat and Mass Transfer 78, 360-370, doi:10.1016/j.ijheatmasstransfer.2014.06.083 (2014).

Wu Kongxiang. Numerical simulation and experimental study of the coupling characteristics between vortex tube and refrigerants. [D] Zhejiang University, (2013).

Han X, Li N, Wu K, et al. The influence of working gas characteristics on energy separation of vortex tube[J]. Applied Thermal Engineering, 2013, 61(2):171-177. He Shu et al. Experimental study on the effect of the inlet pressure on the performance of vortex tube. ACTA AERODYNAMICA SINICA 24, 487-490 (2006).

Ahmet Murat Pinara, Onuralp Uluerb \& Kirmacic., V. Optimizing the Temperature of Hot outlet Air of Vortex Tube using Taguchi Method. International Journal of Refrigeration 32, 1487-1494 (2009).

91 Thakare, H. R. \& Parekh, A. D. Computational analysis of energy separation in counter-flow vortex tube. Energy 85, 62-77, doi:10.1016/j.energy.2015.03.058 (2015). I, G. A. Ranque effect at low temperature. J Eng Phys 9, 242-244 ( 1965).

Bruno, T. Laboratory Applications of the Vortex Tube. Journal of Chemical Education 64, 987-988 (1987).

Wang Zheng. The research of the vortex tube performance and the coupling characteristics with responding refrigeration svstemv[D]. Hangzhou: Zhejiang University, 2013.

Brian Boswell \& Chandratilleke, T. T. Air-Cooling Used For Metal Cutting. American Journal of Applied Sciences 6, 251-262 (2009). 
Manufacturing technology and machine tools, 1997, 1: 30-32.

97 Aznijar Ahmad-Yazid, ZahariTaha \& Almanar, I. P. A review of cryogenic cooling in high speed machining (HSM) of mold and die steels. Scientific Research and Essays 5, 412-427 (2010).

98 Liu Dongxia.cutting experiment and simulation on air cooling and tool design[D]. Harbin: Harbin University Of Science And Technology, 2008.

99 Cong W, Pei Z J . Dry Machining Using Vortex-Tube Generated Cold Air as Coolant: A Literature Review[C]// Asme International Manufacturing Science \& Engineering Conference Collocated with the Jsme/asme International Conference on Materials \& Processing. 2008.

100 Yang Yan, Zhang Jinsong, Xu Minyu, et al. Analysis of Vortex Tube Cooling[J]. FLUID MACHINERY, 2013, 41(7): 81-84.

101 Jinggang W, Xiaoxia G, Shanlin J. The Application of Vortex Tube in Deep Mine Cooling[C]// International Conference on Energy \& Environment Technology. 2009.

102 Tunkel;, L. \& Coffman, J. Vortex Pilot Gas Heater Design Needs No External Energy Source. Pipeline and Gas Journal 234, 65-66 (2007).

103 Li Wei. Numerical simulation of vortex tube and its application[D]. Beijing: North China Electric Power University, 2008

104 Xiong Changzheng, Chen Chuang, Yin Kejiang, et al. Application of heating technology of vortex tube in natural gas industry[J]. OIL\&GAS STORAGE AND TRANSPORTATION, 2009, 28(6): 69-72.

105 C. U. Linderstrbm-Lang, Research Establishment Riser, Roskilde \& Denmark. Gas separation in the Ranque-Hilsch vortex tube. Heat Mass Transfer 7(11), 1195-1206 (1964).

$106 \mathrm{Xu}$ Zhengbin. Application prospect of vortex tube technology in natural gas[J]. OIL\&GAS STORAGE AND TRANSPORTATION , 2009, 28(1), 41-43.

107 Ding Yonggang, Hou yu, Xiong Lianyou. Application of vortex tube[J]. Cryogenics, 2004, 1: 56-59

108 Yun J , Kim Y, Yu S . Feasibility study of carbon dioxide separation from gas mixture by vortex tube[J]. International Journal of Heat and Mass Transfer, 2018, 126:353-361.

109 Burger, A. Introductory investigation of the Ranque-Hilsch vortex tube as a particle separation device for the PBMR[D]. University of Stellenbosch (2010).

110 Mohammadi, S. Farhadi, F. Experimental and numerical study of the gas-gas separation efficiency in a Ranque-Hilsch vortex tube. Separation and Purification Technology 138, 177-185, doi:10.1016/j.seppur.2014.10.022 (2014).

111 Balepin V, Petley D, Rosholt D . Progress in Air Separation with the Vortex Tube[M]. NASA Langley Technical Report Server, 1999. 